\title{
HACIENDA Y GOBIERNO DEL LINAJE EN EL NUEVO ORDEN DE COSAS. LA GESTTÓN PATRIMONIAL DE LOS MARQUESES DE SAN ADRIÁN DURANTE EL SIGLO XIX ${ }^{1}$
}

\author{
JOSÉ MIGUEL LANA BERASAIN \\ Universidad Pública de Navarra
}

\section{RESUMEN}

Un estudio de caso centrado en un linaje señorial de la aristocracia de base regional permite examinar la adaptación de las elites feudales al nuevo orden surgido de la revolución liberal. Se pone especial énfasis en las dificultades de los señores durante esa etapa, así como en la variedad y complejidad de situaciones y desenlaces, que no impidieron la recomposición de sus fundamentos económicos bajo nuevas bases. Con una doble estrategia como rentistas, que no absentistas, y cultivadores/industriales, las rentas patrimoniales de esta familia pudieron crecer durante la segunda mitad del siglo XIX.

\section{ABSTRACT}

Through the case of one family from the regional nobility, this paper examines the adaptation of the old landowner elites to the new board carried by the Liberal Revolution. Despite the large struggle against the manorial power and other contingencies, the Magallon procured to repair their fortune on a new basis. With a double strategy such as lessors and husbandmen,

N. de E.: Fecha de recepción del artículo: mayo, 2001.

Fecha de aprobación por el Consejo de Redacción: octubre, 2002.

1 Una versión previa de este trabajo fue presentado al VII Congreso de la Asociación de Historia Económica (Zaragoza, 2001), habiendo sido antes discutida en un seminario convocado en Valladolid por los organizadores de la sesión. Agradezco a Ricardo Robledo, Hilario Casado, Iñaki Iriarte y Joseba de la Torre, así como a los evaluadores de esta Revista, su atenta lectura y sus sugerencias. Los errores sólo a mí competen. 
their incomes rose during the second half of the XIx century. Indeed, they were very far from the arguable Spanish stereotype of the absent landowner. JEL Classification: N53, N83, D21, Q12.

\section{DE RICOSHOMBRES DEL REINO A GRANDES DE ESPAÑA: EL ASCENSO DE UNA ARISTOCRACIA DE SEGUNDO ORDEN}

Cuando a fines del siglo Xvin José María Magallón y Mencos pretendiera, además de proteger y actualizar sus rentas, acceder a los más altos honores, solicitando a la Corona la concesión de la Grandeza de España y a las Cortes de Navarra el reconocimiento del vetusto honor de Ricohombre del Reino, requirió el auxilio del polígrafo tudelano Juan Antonio Fernández para poner orden en sus archivos y expresar su estirpe en un relato plausible. El cronista por encargo retrotrajo su narración hasta el siglo XII tomando como tronco o hilo conductor el linaje cispirenaico de Gramont, feudatario de los reyes de Navarra y receptor por su cercanía a la Corte durante los siglos XIV y XV de diversas mercedes reales. Entre ellas se contaba la concesión de la villa y castillo de Monteagudo «con todos sus derechos territoriales, solariegos y jurisdiccionales y demás regalías que en ella eran correspondientes a los Monarcas», además de otros derechos señoriales en la vecina Cascante, por un real privilegio de 2 de junio de 1429 otorgado a favor de Florestán D’Agramont y Leonor Frangel. Azares biológicos hicieron mudar la estirpe, todavía en el siglo xv, de Agramont a Beaumont de Navarra y, ya durante el siglo xvi, de ésta a Magallón, por matrimonio de María de Beaumont-Navarra y Pedro Magallón, señor de San Adrián ${ }^{2}$.

El apeo y valuación general de bienes confeccionado a comienzos del siglo XVI para resolver el pleito entre las merindades por el reparto de cuarteles ofrece una imagen del patrimonio, vinculado por vez primera en 1485, que la donación regia de 1429 había proporcionado a la familia. Para entonces, la decidida oposición de la villa de Cascante había vencido al linaje en su pretensión de intitularse señores de la misma. Los derechos señoriales de la casa deberían limitarse, una vez unidas las estirpes de

\footnotetext{
${ }^{2}$ Sobre el señorío de San Adrián, otorgado en 1454 y confirmado en 1494, vid. Yanguas y Miranda (2000, pp. 1024-1025). El relato aludido constituiría la Representación al Rey nuestro Señor que bace don José Maria Magallón y Mencos Ayanz de Navarra, Señor y Marqués de San Adrián, exponiendo en ella la calidad, méritos y servicios de sus progenitores y propios, suplicando a $S . M$. que en atención a ellos se digne conferirle la grandeza de primera clase. Madrid, Imp. Viuda de Ibarra, 1799.
} 
Beaumont y Magallón, y sin otro título que el de meros señores, a las localidades de Monteagudo y de San Adrián. Pero antes de que ese siglo tocase a su fin, el linaje se vería favorecido por la largueza en la concesión de títulos que caracterizó al reinado del último Austria. Con el marquesado de San Adrián otorgado a Joaquín de Magallón y Beaumont en 1696, la estirpe contó con el capital simbólico necesario para brillar con luz propia durante el Dieciocho. Y fueron, en efecto, los ilustrados y activos Francisco Magallón Magallón y su hijo y sucesor José María Magallón y Mencos, quienes llevarían a la casa a las puertas de la Grandeza de España, obtenida finalmente en $1802^{3}$.

Mientras se desarrollaba esta carrera ascendente fundada en la sangre y en el mérito, los miembros del linaje mantuvieron su apego al país en su residencia tudelana. No estamos ante una nobleza cortesana ni ante ningún señor ausente. Exceptuando servicios de armas o eventuales distracciones, los Magallón permanecieron cerca de sus Estados y mayorazgos, por otra parte cortos en comparación con los de la gran nobleza castellana. Pero Magallón y Mencos, aupado a la Grandeza más por sus méritos que por sus rentas, sería el último marqués tudelano. A su hijo José María Magallón Armendáriz, oportunamente casado en 1790 con la viuda M. ${ }^{a}$ Soledad Isidra Rodríguez de los Rios, marquesa de Santiago y La Simada (retratados ambos por Goya en 1804), sus aspiraciones cortesanas, primero, y los avatares a que le condujo su compromiso afrancesado ${ }^{4}$, después, le mantuvieron alejado de sus dominios. Ni él ni sus sucesores volverían a arraigar en el país, limitándose a estancias más o menos prolongadas, ya no en Tudela, sino en Monteagudo.

Pero, ¿qué cimientos económicos sostenían esta carrera ascendente? El testimonio que el apoderado general de la casa, Martín de Irurtia, presentaba en junio de 1799 ante el notario Lucas de Rivas, de los frutos, rentas y censos ingresados durante el último quinquenio por los «mayorazgos y Estados» del sexto marqués, recién fallecido, arrojaba unos ingresos brutos de 280.431 rs. vn., de los que 131.806 rs. vn. (el 47 por 100) procedían de sus señoríos de Monteagudo y San Adrián. Esas dos administraciones aportaban el 45 por 100 del trigo que ingresaba en sus paneras por vía de rentas, la misma proporción de las cosechas de vino de la casa, el 52 por 100 de su producción de aceite y el 29 por 100 del dinero que proporcionaban los alquileres. El resto procedía del patrimonio radi-

${ }^{3}$ Astigarraga (1992) y Sola Lasheras (1998), Gran Enciclopedia de Navarra (1993, pp. VII, 180-181).

${ }^{4}$ Mercader Riba (1983, pp. 70, 323). 


\section{CUADRO 1}

Valuación de los bienes de don Juan Fermín de Beaumont-Navarra en Monteagudo y Cascante, 1607

\begin{tabular}{|c|c|c|c|c|c|c|c|c|}
\hline & \multicolumn{2}{|c|}{ Monteagudo } & \multicolumn{2}{|c|}{ Cascante * } & \multicolumn{4}{|c|}{ Total } \\
\hline & $\mathrm{Ha}$. & Ducs. & $H a$. & Ducs. & $\mathrm{Ha}$. & $\%$ & Ducs. & $\%$ \\
\hline Agostíos....................... & 51,93 & 25.300 & 25,61 & 9.470 & 77,54 & 18,1 & 34.770 & 31,8 \\
\hline Barbechos .................. & 128,57 & 24.860 & 54,40 & 11.420 & 182,97 & 42,7 & 36.280 & 33,2 \\
\hline 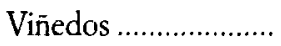 & 9,43 & 2.100 & 4,40 & 1.150 & 40,61 & 9,5 & 3.250 & 3,0 \\
\hline Huertos ....................... & - & - & 3,32 & 2.280 & 3,32 & 0,8 & 2.280 & 2,1 \\
\hline Sotos & 6,29 & 700 & 0,18 & 70 & 6,47 & 1,5 & 770 & 0,7 \\
\hline Prados y yermos ....... & 44,92 & 5.000 & 2,43 & 27 & 47,35 & 11,1 & 5.027 & 4,6 \\
\hline Bienes rústicos .......... & 241,14 & 57.960 & 90,34 & 24.417 & 358,26 & 83,7 & 82.377 & 75,5 \\
\hline Bienes urbanos.......... & - & 17.350 & - & 3.600 & - & - & 20.950 & 19,2 \\
\hline Bienes a censo............ & 12,67 & 1.825 & 56,98 & 4.000 & 69,65 & 16,3 & 5.825 & 5,3 \\
\hline Valor Total.. & 253,81 & 77.135 & 147,32 & 32.017 & 427,91 & 100,0 & 109.152 & 100,0 \\
\hline
\end{tabular}

* No se incluye la valuación de los bienes rústicos (9,97 ha. y 4.350 ducados) y urbanos (1.400 ducados) de su madre, Bernardina del Río y Mendoza, en Cascante.

Datos en hectáreas y en ducados navarros.

Fuentes: AGN, Comptos, Papeles sueltos, Valuaciones de bienes de 1607.

cado en el realengo. Confluian, pues, en el mismo linaje dimensiones muy diversas, entre las que el poder señorial representaba tan sólo una parte, asemejándose en otros rasgos a esa otra nobleza procedente del patriciado urbano que había ido fundando, reuniendo y ampliando mayorazgos (quince en este caso) a lo largo del período tardofeudal ${ }^{5}$.

Heterogénea era, también, la estructura de sus rentas: ingresos procedentes de derechos o contratos feudales convivían con rentas procedentes de una propiedad, vinculada o libre, bien delimitada, que se venían negociando en el mercado de alquileres. Derechos y monopolios de naturaleza feudal, como los molinos de Monteagudo y San Adrián, la barca de este último pueblo y el horno del primero o las vecindades foranas de Ribaforada, se arrendaban periódicamente al mejor postor. A las cesiones temporales de tierras y casas, sueltas o en forma de quiñones, por la vía del arrendamiento, bien en grano, bien en dinero, se unían las enfiteusis, y los derechos señoriales en forma de partes de frutos (diezmos, ochenos, cuar-

\footnotetext{
${ }^{5}$ El informe de Irurtia, en AMSA, sección General, lg. 6/7. c. 5.
} 
tos,... en Monteagudo) o en forma de pecha fija (San Adrián). Renta feudal y renta capitalista, entrelazadas o superpuestas, confluían sin solución de continuidad en las mismas administraciones ${ }^{6}$.

\section{UN TIEMPO DE ZOZOBRAS Y OPORTUNIDADES}

\subsection{El señor acosado. La lucha antifeudal en los dominios de los Magallón}

El linaje había culminado en las últimas décadas del siglo xvII un prolongado proceso de ascenso social, pero es también en esas fechas cuando la contestación al señor, que no había faltado en épocas pretéritas, comenzó a cobrar unas dimensiones amenazadoras que estallarían después de 1808 . Si podía caberle alguna duda al marqués sobre la ineficacia de los medios coercitivos de la jurisdicción señorial para garantizar la extracción del excedente, los hechos acontecidos en San Adrián y Monteagudo durante el último tercio del siglo XVIII - cuando el ciclo de crecimiento dieciochesco mostraba claros signos de desfallecimiento, durante lo que Tello ha denominado el último ciclo de la renta feudal ${ }^{7}$ - , hicieron patente la debilidad de tales mecanismos. Es más, los resortes encargados de garantizar la pervivencia de la explotación feudal, fuesen éstos de carácter político o simbólico, se habian convertido ellos mismos en el principal nudo de contestación por parte de las comunidades locales.

Aunque la lucha antiseñorial cobraba cuerpo también en Monteagudo por la vía de los pleitos ${ }^{8}$, iba a ser en San Adrián donde el desencuentro iba a tomar tintes más dramáticos. El pulso mantenido en torno a los derechos de propiedad sobre los sotos y sobre las dehesas del monte en

${ }^{6}$ Artola (1979, pp. 71-85) destacaba el carácter capitalista del extendido sistema de alquileres o arrendamientos aunque gravitase sobre bienes de origen feudal, lo que le permitía definir a la sociedad del Antiguo Régimen como una mixtura de rasgos precapitalistas y capitalistas.

7 Tello (1992, pp. 296-297). Véase también Tello (1997).

${ }^{8}$ En 1789 se ventilaba ante la Real Corte una querella interpuesta por el marqués y su alcalde mayor contra la villa y sus regidores, por haber estorbado éstos «que el referido alcalde amugase las yerbas en que debía pacer el ganado menudo virolento» (AGN, Real Corte, tomo 110, Ochoa, lg. 3076). Así es que en 1797 el Censo de Godoy aclaraba que aunque Magallón «se titula Señor de ella... se lo tienen protestado los vecinos» (AGN, Estadística, lg. 20/28). Martínez Monje (1947, pp. 302-340) recoge por extenso el pulso mantenido en torno al patronato de la basílica de la Virgen del Camino entre la villa y los marqueses en 1753-1764 y en 1790-1791. 
un contexto de presión roturadora ${ }^{9}$ culminaron en la primavera de 1795 en una escalada de enfrentamientos competenciales y simbólicos entre la justicia señorial y el regimiento de la villa. La noche del 2 de junio de ese año una multitud sin muchas más armas que la cólera se amotinó y asedió durante cinco horas la casa del alcalde mayor, donde se habían refugiado éste y otros cargos nombrados por el señor, dejando como saldo dos cadáveres, algunos heridos y las familias de los sitiados obligadas a exiliarse. Las cuentas del marqués acusan los efectos del motin: entre 1796 y 1798 se acumularon atrasos tanto en los arrendamientos de heredades como en la pecha anual de trigo y cebada que mancomunadamente debía la villa, y la sustitución masiva de arrendamientos por aparcerías en 1797 parece apuntar a un desahucio colectivo ${ }^{10}$. Pese a lo que quisiera creer el apoderado del marqués, que cuatro años después del motín lo atribuía a la imprudencia del alcalde mayor, lo que en el conflicto se jugaba era la capacidad de unos y otros para aprovechar en su beneficio el tirón de la fase económica expansiva y, más lejos aún, lo que se ponía en duda era el mismo hecho de la coacción señorial como mecanismo de control social.

El colapso provocado por la ocupación napoléonica, en la que jugó un importante papel como político y cortesano José M. ${ }^{a}$ Magallón Armendáriz, y las novedades legislativas procedentes tanto de Bayona como de Cádiz no harían sino precipitar la crisis del dominio señorial. De lo excepcional de las circunstancias y de lo vulnerable del viejo orden dan fe las limosnas forzadas al vecindario que, por un volumen de $82 \mathrm{hl}$. de trigo, se vio obligado a aprobar el marqués en 1808,1814 y 1815 con el fin de «aplacar los tumultos». Ello no evitaría que se lo tomasen por su mano más tarde, aprovechando las sombras de la noche (566 litros de aceite

${ }^{9} \mathrm{E}$ l intento en 1768 de roturar y poner en cultivo mediante reparto el soto Bergal fue bloqueado por el Señor y por los grandes hacendados con intereses ganaderos -con los argumentos de la reducción de hierbas y rentas de propios y de la insuficiencia del caudal de la presa para satisfacer el regadío antiguo, el molino señorial y las nuevas parcelas-, pero merced a una treta de los representantes vecinales pudo ser aprobado finalmente en 1790 (Floristán Imízcoz, 1982, pp. 288 y 308). En 1795 se trataba de roturar y repartir terrenos en las corralizas de Muga de Azagra, Muga de Andosilla y la Dehesa, y fue en una reunión celebrada en mayo con ese objeto cuando el alcalde ordinario y otros sujetos impidieron el uso de la palabra al alcalde mayor, nombrado por el señor, diciendo «que no lo reconocían ni respetaban sino como un mero administrador del marqués» (AMSA, cj. 20/14).

${ }^{10}$ En 1796 y 1797 se acumularon como atraso de rentas $181 \mathrm{hl}$. de trigo, sobre los $135 \mathrm{hl}$. ingresados normalmente, sin que pudieran recuperarse más que $22 \mathrm{hl}$; ; en 1798 la villa sólo entregó un 42 por 100 del grano que debía de pecha y en 1800 nada (AMSA, cj. 20/14). 
robaban en 1816 tras romper las puertas de la almazara) o aplicando la autoridad de un ayuntamiento ahora independiente del señor (en 1817 le descerrajaban las puertas de la bodega para embargarle otros 728 litros). En la incierta etapa que se inauguraba, la posición del señor se vería atacada desde varios flancos. El nuevo principio de fiscalidad general y proporcional llevaría a los pueblos a exigirles a sus señores su contribución de buen grado o por la fuerza: si en Monteagudo se embargaba el aceite, en San Adrián el ayuntamiento violentaba en 1820 sus graneros y le retenía 173 hl. de trigo para pago de las contribuciones de guerra. Además, la nueva legalidad constitucional permitía obviar los monopolios banales respetados hasta entonces: así ocurría con la regalía de la barca de sirga sobre el Ebro en San Adrián ${ }^{11}$, mientras que en el otro señorio desaparecía también una renta banal «a causa de que los vecinos de Monteagudo han construido hornos particulares en sus casas por suponer que les da ese derecho la Constitución de la Monarquía Española». Por otro lado, la voceada abolición del feudalismo invitaba a los hasta entonces vasallos a omitir los odiados tributos: sin que sepamos que ocurre entre 1800 y 1814 (por no haber podido localizar la documentación contable), en ese último año y en el siguiente la pecha de San Adrián no pudo cobrarse, y aunque entre 1816 y 1820 se regularizó el cobro y se recuperaron algunos atrasos, con el Trienio dejaba nuevamente de pagarse.

Defender los derechos de la casa en semejantes circunstancias iba a obligar a enormes desembolsos ante los tribunales, especialmente durante la década de 1820. En algunos casos, éstos fallarían en su contra ${ }^{12}$; en otros, se vería parcialmente favorecido ${ }^{13}$; en ocasiones, por último, llegarían

"Confiscada primero por la División de Navarra comandada por Espoz y Mina (De la Torre, 1991, pp. 83-84) y luego por el ayuntamiento constitucional (APN, Azagra, A. Hernández, 1820, lg. 87), fue destruida preventivamente por el ejército liberal en 1834, y no llegó a reconstruirse porque «interín se practicaban estas diligencias colocaron otra algo más arriba los Ayuntamientos del mismo San Adrián y Calaorra» y «consultado el asunto opinaron los letrados... que el Marqués tenía derecho a restablecer la Barca si le acomodaba pero que no podía impedir que los Pueblos pusieran la suya» (AMSA, cj. 44/1).

12 En 1828 los tribunales condenaban al marqués, en tanto que propietario del molino, a contribuir con cantidades importantes a las obras de una presa y cauce para derivar aguas del río Ebro al nuevo regadío de Bergal. Ese mismo año otra sentencia aprobaba el embargo y subasta judicial de sus rentas de San Adrián para completo pago del reparto de la Junta de Regadío (AMSA, cj. 1/5; cj. 22/8).

${ }^{13}$ Una Sentencia de 3 de julio de 1844 declaraba abolida la pecha, pero obligaba al ayuntamiento a abonar los atrasos acumulados hasta el 2 de febrero de 1837: $188 \mathrm{hl}$. de trigo y $205 \mathrm{hl}$. de cebada (equivalentes a nueve o diez anualidades) que recaerian sobre unas arcas municipales exhaustas. Tras algunos arreglos transitorios, en 1855 se alcanzaba un pacto entre el ayuntamiento y el marqués por el que éste recibiria $6.799 \mathrm{rs}$. vn. en 
a alcanzarse acuerdos satisfactorios para ambas partes. Sucedió esto último en Monteagudo, donde la villa había intentado por dos veces, y acogiéndose a la legislación sobre reparto de baldíos, romper y repartir los prados alto y bajo del Baire y Ginester, siéndole impedido por sendas sentencias del Tribunal de la División de Navarra en 1812 y del Tribunal del Partido en 1820 . En octubre de 1822 firmaban finalmente un convenio que daba vía libre al repartimiento de 31 ha. entre 136 vecinos, quienes obtenían un usufructo exento de renta durante veinticinco años, pasados los cuales abonarían un canon fijo de «medio robo de trigo puesto en panera por robo de tierra». Visto de otra forma, el marqués conseguía un reconocimiento de propiedad a cambio de no exigir renta alguna hasta 1848 , y cobrando un módico alquiler no actualizable desde esa fecha ${ }^{14}$.

Así es que cuando en 23 de agosto de 1837 se promulgó la ley abolitoria del régimen seriorial (Hernández Montalbán, 1999), las respectivas posiciones del viejo señor y de las villas parecían haberse clarificado a través de tres decenios de agónicos desencuentros. En Monteagudo, donde los Magallón contaban con bases más firmes, que eran garantizadas además por una prudente política, pudieron confirmar por sentencia de 29 de marzo de 1838 una propiedad plena sobre la mayor parte del término. En San Adrián, donde la contestación al señor había sido más tenaz, y hasta cruenta, y donde esa hostilidad persistiría durante «el nuevo orden de cosas», el marqués hubo de contentarse con la propiedad de 25 ha. de regadío, unos pocos solares y el molino, perdido ya todo monopolio de molturación ${ }^{15}$.

\subsection{Más allá del mayorazgo. Prácticas sucesorias y estrategias patrimoniales}

Entendida la familia no como hogar sino como linaje, las estrategias reproductivas de los marqueses de San Adrián no podían limitarse a garantizar el mantenimiento de las condiciones económicas que habían sostenido

dos plazos iguales para completar el pago (APN, Azagra, F. J. Echarte, 1855, lg. 105/60, 1856, lg. 105/16).

${ }_{14}$ AMSA, cj. 20/1.

15 En unas Notas y observaciones sobre las Administraciones del Marquesado de San Adrián de octubre de 1843 recelaba Magallón de que la hostilidad del vecindario podría prolongarse «a causa del nuevo orden de cosas y régimen político del día» (AMSA, cj. 22/8). Usunáriz (1997, pp. 280-281) atribuye la incapacidad de los señores navarros para transformar las pechas en arrendamientos a la resistencia de los pecheros $-\mathrm{y}$ principalmente de los hidalgos sujetos a pecha- a reconocer en ello un dominio eminente. 
a la casa en una determinada posición social. Existía además una dimensión de poder y prestigio, de honor, ejercida hacia abajo y exhibida hacia arriba en la escala social, que se hacía necesario preservar y, si resultaba posible, ampliar. Claro que esto último difícilmente podría verificarse sin gozar de unas rentas seguras y estables. La institución del mayorazgo había venido a resolver para los linajes ese problema, anteponiendo la estirpe a los individuos que la componían y fijando una normativa sucesoria que anulaba enfrentamientos y arbitrariedades. Pero a finales del siglo XVIII tal institución se hallaba en una encrucijada: si una parte de las críticas pretendían impedir la proliferación de mayorazgos pobres de origen hidalgo o burgués, otras voces reclamaban un mayor margen de maniobra para los titulares a fin de racionalizar o sanear patrimonios de aluvión, y no faltaban quienes en nombre de la libertad de mercado se atrevían a negar el principio de vinculación. Lo cierto es que en las últimas décadas del siglo y de la mano también de los apuros de la Hacienda Real se dictaron algunas disposiciones - extendidas algunas de ellas a Navarra por las sucesivas Cortes- que tendían a liberalizar el régimen de mayorazgo y que conducirían más tarde (en 1820 y definitivamente en 1836) a la abolición del mismo ${ }^{16}$.

Coincidiendo con este proceso, cargado de incertidumbre, que sometió a revisión los modelos de reproducción social de los linajes, José María Magallón y Armendáriz tendría que hacer frente a algunos sobresaltos añadidos que, derivados de tres muertes consecutivas, alteraron gravemente, y por distintas razones, sus expectativas. La primera muerte perturbadora fue la de su propio padre, o más que ella, lo inusual de sus últimas voluntades, ya que estipulaba un reparto igualitario de la herencia entre sus cinco hijos. No parece fácil determinar qué pudo empujar al ilustrado Magallón y Mencos a tomar semejante decisión, aunque no deja de ser significativo que la crítica al mayorazgo y el ejemplo francés de herencia igualitaria, plasmado pocos años después en el Code Civil, encontrasen eco en uno de los principales representantes de las Luces. Tras no pocos enfrentamientos familiares y gestiones de abogados, el asunto pudo resolverse conservando los derechos del primogénito a cambio del mantenimiento generoso por vía de alimentos de sus hermanas y hermano mientras permaneciesen solteros ${ }^{17}$. La segunda muerte, la de su esposa en 1807 , con-

${ }^{16}$ Clavero (1974, pp. 291-311, 361-384), Pérez Picazo (1990, pp. 121-127), Parias (1991, pp. 38-42).

17 Poco después, entre 1802 y 1805, se encargaría el marqués consorte de Santiago de casar a sus hermanas en el exclusivo círculo de la aristocracia. El episodio lo recoge Sola Lasheras (1998). 
dujo, a causa de la falta de entendimiento con sus hijastros, los marqueses de Piedrablanca, a un largo periplo judicial que culminó en 1813 en un secuestro judicial de sus bienes y mayorazgos. Tanto ese secuestro como la eventual incautación tras el regreso del absolutismo fernandino y el obligado exilio bordelés de Magallón, pudieron conjurarse en 1815 merced a una maniobra que depositaba en su heredera Francisca de Paula todos los derechos del séptimo marqués. La tercera muerte, demoledora para éste, significó la ruptura de su línea legítima de sucesión además de un profundo dolor personal, al fallecer su única hija legítima, la citada condesa de Sástago, en el parto de su nieto nonato ${ }^{18}$.

\section{CUADRO 2}

Compraventas de patrimonio de los marqueses de San Adrián durante el siglo XIX (datos en miles de reales vellón)

\begin{tabular}{|c|c|c|c|c|c|c|c|}
\hline & \multicolumn{2}{|c|}{ Bienes rústicos } & \multicolumn{2}{|c|}{ Bienes urbanos } & \multicolumn{2}{|c|}{ Total } & \multirow{2}{*}{ Saldo } \\
\hline & Ventas & Compras & Ventas & Compras & Ventas & Compras & \\
\hline $1801-1810$. & 7,54 & 218,70 & 4,50 & 64,91 & 12,03 & 283,61 & $+271,58$ \\
\hline $1811-1820 \ldots \ldots \ldots$ & 90,23 & 2,89 & 8,00 & 6,38 & 98,23 & 9,27 & $-88,96$ \\
\hline $1821-1830 \ldots \ldots \ldots$ & 262,84 & 0,69 & 49,80 & 一 & 312,64 & 0,69 & $-311,95$ \\
\hline $1831.1840 \ldots \ldots \ldots$ & 232,77 & 7,87 & 6,00 & 69,28 & 238,77 & 77,15 & $-161,62$ \\
\hline $1841-1850 \ldots \ldots \ldots$ & 116,77 & 334,34 & 29,66 & 121,15 & 146,42 & 455,49 & $+309,07$ \\
\hline $1851-1860 \ldots \ldots \ldots$ & 58,16 & 20,25 & 5,52 & 7,14 & 63,67 & 27,39 & $-36,28$ \\
\hline $1861-1870 \ldots \ldots \ldots$ & 5,23 & 104,19 & 3,24 & 23,40 & 8,47 & 127,60 & $+119,13$ \\
\hline $1871-1880 \ldots \ldots \ldots$ & - & 23,14 & - & 16,11 & - & 39,25 & $+39,25$ \\
\hline $1881-1890 \ldots \ldots \ldots$ & 12,44 & 7,15 & - & - & 12,44 & 7,15 & $-\quad 5,29$ \\
\hline $1891-1900 \ldots \ldots \ldots$ & - & 78,85 & 7,00 & 66,37 & 7,00 & 145,22 & $+138,22$ \\
\hline Total ......................... & 785,98 & 798,08 & 113,72 & 374,75 & 899,69 & $1.172,83$ & $+273,14$ \\
\hline
\end{tabular}
t. $2 / 2$.

Fuente: Cuadernos de compras y ventas de patrimonio, AMSA, cị. 36/9; e Indiferentes,

Amargado por esas ausencias, por los zarandeos que le propinó la política, por la levantisca actitud de sus vasallos, por el exilio, por los apuros económicos, por un mundo que se había venido abajo, moriría este hombre en junio de 1845, pasando sus títulos y mayorazgos, por orden de sucesión,

${ }^{18}$ Una cuarta muerte, la de Nicolás de Armendáriz en 1815 , resultó más afortunada para la casa, ya que derivó hacia los Magallón los bienes del marquesado de Castelfuerte. 
a su hermano Joaquín Mariano. Para entonces, sin embargo, se había conseguido sanear y estabilizar la situación del patrimonio y, tras una diligente participación en los mercados de la tierra —que no excluía las ventas de patrimonio vinculado, previa tramitación ante el Real Consejo de Navarra y subrogando siempre por un valor equivalente-, la casa disponía de una masa de bienes más compacta y manejable, y de unas buenas expectativas en lo que se refiere a los ingresos ${ }^{19}$.

Ignoro cuándo se procedió a la desvinculación y partición de los mayorazgos de la casa, pero pudo tener lugar hacia 1853, cuando del tronco patrimonial se segregaron las administraciones de Tulebras y Los Arcos para dotar al primogénito: Joaquín Magallón Campuzano. Dos años más tarde, su padre le traspasaba también el título honorífico de marqués de Castelfuerte -pero no los bienes de la administración de Aoiz a los que había estado asociado hasta entonces-, de modo que uno y otro, padre e hijo, podrían desenvolverse cómodamente en el espacio social y político que el nuevo orden liberal reservaba a las elites de la sangre, junto a las de la riqueza y las del talento. Las veleidades del reparto igualitario que habían afectado a Magallón y Mencos no volverían a reaparecer. Las prácticas hereditarias durante el Ochocientos, abolidos legalmente los mayorazgos y escriturada la desvinculación de los del linaje Magallón, responderían a lo que Parias ha denominado estrategias vinculares, recurriendo si fuera preciso a prácticas endogámicas. A la muerte del noveno marqués y de su esposa en 1864 y 1866, respectivamente, el tronco del patrimonio volvía a fundirse en el primogénito, aunque se segregaban bloques compactos del mismo, por valor de una cuarta parte, para dotar a sus hermanos menores. Antes de terminar el siglo, azares biológicos permitieron que nuevamente se recompusiese el patrimonio original de la casa en 1894 en la persona de José María Magallón Campuzano ${ }^{20}$.

Los inventarios de rentas anuales de la casa que se formalizaron a la muerte de José María Magallón Armendáriz y de su sucesor en 1845

${ }^{19}$ La política de compraventas de la casa y la remodelación física y funcional del patrimonio reciben una atención específica en Lana Berasain (2002).

${ }^{20}$ Parias (1991). Añadiendo a Tulebras y Los Arcos, que ya disfrutaba, las administraciones de Monteagudo, Cascante y San Adrián, Joaquín Magallón Campuzano, quien se había casado en 1849 con su prima Adriana Magallón Moreno (hija natural del séptimo marqués y heredera de sus bienes libres) reunía el 75 por 100 de los ingresos evaluados en la escritura de 1845 . El resto quedaba para sus hermanos José María (bienes de Tudela, Peralta y Aoiz) y Ana María (Corella y Cintruénigo), recibiendo Pilar, Regina y Josefa compensaciones en metálico. La muerte sin descendencia de Ana $M^{2}{ }^{a}$ en 1887 revertiría al décimo marqués los bienes del valle del Alhama, mientras que la muerte de éste, también sin hijos, en 1894 favorecía a su hermano José M. ${ }^{a}$, marqués de Castelfuerte desde 1876. 


\section{CUADRO 3}

Estado de los productos de la casa del marqués de San Adrián a la muerte de José Maria y de Joaquin Mariano Magallón Armendáriz, según las relaciones formadas en 29 de julio de 1843 $y$ en 13 de marzo de 1864

\begin{tabular}{|c|c|c|c|c|c|c|}
\hline & \multicolumn{3}{|c|}{ Circa 1843} & \multicolumn{3}{|c|}{ Circa 1864} \\
\hline & $H l$. & Rs. vn. & $\%$ & $H l$. & Rs. vn. & $\%$ \\
\hline entas en trigo.... & $1.470,64$ & 72.540 & 42,3 & $1.159,52$ & 77.708 & 31,7 \\
\hline Censos en trigo & 158,65 & 8.083 & 4,7 & 211,82 & 14.338 & 5,8 \\
\hline Cosecha de vino & 435,49 & 11.100 & 6,5 & 353,10 & 21.000 & 8,6 \\
\hline Cosecha de aceite ............................ & 188,93 & 54.880 & 32,0 & 237,05 & 89.936 & 36,6 \\
\hline Venta de huesillo ............................ & 70,33 & 375 & 0,2 & 216,60 & 1.125 & 0,5 \\
\hline 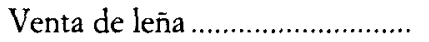 & - & - & - & - & 2.900 & 1,2 \\
\hline Rentas en dinero ............................. & - & 18.493 & 10,8 & - & 31.860 & 13,0 \\
\hline Censos en dinero ........................... & - & 1.878 & 1,1 & - & 1.972 & 0,8 \\
\hline Réditos de préstamo & - & - & - & - & 250 & 0,1 \\
\hline 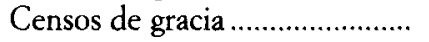 & - & 4.187 & 2,4 & - & 4.308 & 1,8 \\
\hline Ingresos administraciones.......... & - & 171.536 & 100,0 & - & 245.397 & 100,0 \\
\hline 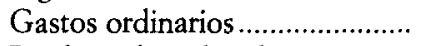 & - & 81.650 & 47,6 & - & 100.626 & 41,0 \\
\hline Producto líquido admones. ...... & - & 89.886 & 52,4 & - & 144.771 & 59,0 \\
\hline Censos contra bienes libres ....... & - & 4.504 & 2,6 & - & - & - \\
\hline os.......... & - & 5.238 & 3,1 & - & 4.398 & 1,8 \\
\hline Lanzas de la Grandeza ................. & - & 3.600 & 2,1 & - & - & - \\
\hline Deuda bienes nacionales ............ & - & 17.000 & 9,9 & - & 20.971 & 8,5 \\
\hline Gastos generales ............................. & - & 8.000 & 4,7 & - & 7.000 & 2,8 \\
\hline Curiales & - & 2.000 & 1,2 & - & - & - \\
\hline Pensiones y asignaciones ........... & - & 5.110 & 3,0 & - & 11.120 & 4,5 \\
\hline Réditos de préstamos................ & - & 5.514 & 3,2 & - & - & - \\
\hline Total de cargas fijas generales. & - & 50.966 & 29,7 & - & 43.489 & 17,7 \\
\hline Producto líquido general ........... & - & 38.920 & 22,7 & - & 101.282 & 41,3 \\
\hline
\end{tabular}

Nota: En 1843 se incluyen las administraciones de Monteagudo, Cascante, Tudela, Corella, Cintruénigo, San Adrián, Los Arcos, Tulebras, Peralta y Castelfuerte (Aoiz). En 1864 todas ellas, salvo Los Arcos y Tulcbras.

FuENTE: AMSA, Indiferentes, núm. 2, lg. 3. 
y en 1864, respectivamente, ofrecen un retrato de la estructura de ingresos y gastos de la casa tras el ciclo revolucionario. El primer dato destacable es el deterioro que, en relación a 1799 , se percibe en los ingresos brutos de la casa: en conjunto, se ingresaban $92 \mathrm{hl}$. de trigo y 2.399 reales menos por vía de rentas y también se había reducido en $135 \mathrm{hl}$. la cosecha anual de vino, aunque se compensaba con $103 \mathrm{hl}$. más en la cosecha de aceite. A ello hay que añadir la caída de los precios agrícolas durante ese difícil medio siglo, que redujo el valor de los ingresos de la casa en un 40 por 100 hasta 1843. Pero más allá de esas mermas ligadas al patrimonio o a los mercados, o precisamente por ello, la composición de ingresos y gastos de las administraciones particulares y general durante las décadas centrales del siglo revela un esfuerzo de ajuste y saneamiento que terminaría por prometer mejores perspectivas. Las principales líneas de cambio hay que buscarlas, en primer lugar, en la composición del ingreso, donde el cultivo directo de olivares y viñedos ganó terreno (del 38,7 al 46,9 por 100) al mero cobro de rentas en grano, si bien merece destacarse también la recuperación de censos y la ampliación de los alquileres en dinero. Un segundo aspecto a destacar es el ajuste del gasto ordinario de las administraciones, que permitió rebajarlo desde el 47,6 al 41 por 100 del ingreso ordinario e incrementar, en consecuencia, el producto líquido desde el 52,4 hasta el 59 por 100. En último lugar, se perciben también cambios en la composición del gasto de la administración general, con una minoración de la deuda censal e hipotecaria, de los gastos de tribunales y del sueldo del administrador general ${ }^{21}$. Es destacable también la partida reservada al pago de los bienes nacionales adquiridos en Tulebras y Tudela con ocasión de las leyes de Mendizábal y Madoz, así como el incremento de las pensiones y asignaciones a parientes y a antiguos empleados, pero en conjunto la reducción de estos gastos generales (es posible que hayan dejado de anotarse en 1864 algunas partidas abonadas por alguna otra vía) permitió incrementar el producto líquido del patrimonio desde el 22,7 por 100 de 1843 hasta el 41,3 por 100 de 1864.

Sin abandonar el análisis de la composición del ingreso y de la renta del linaje, existe un último dato que conviene destacar, esta vez desde una perspectiva espacial. No es otro que la creciente concentración del

${ }^{21}$ Ya en 1843 le había reducido el sueldo a Antonio López de Goicoechea de diez mil a ocho mil reales, con el pretexto de que «cúando los apuros de mi Casa son tan claros y manifiestos y su dueño por esta causa tiene que vivir con su familia en la mayor estrechez atendida su clase y categoría, justo y necesario es que los dependientes se hagan aquellas prudentes economías que sean susceptibles» (AMSA, cj. 17). 


\section{CUADRO 4}

Ingresos medios anuales de la casa del marqués de San Adrián

\begin{tabular}{|c|c|c|c|c|c|c|c|c|c|c|}
\hline \multirow{3}{*}{ Administración } & \multicolumn{6}{|c|}{ Ingreso total } & \multicolumn{4}{|c|}{ Producto liquido } \\
\hline & \multicolumn{2}{|c|}{$1794-1798$} & \multicolumn{2}{|c|}{ Circa 1843} & \multicolumn{2}{|c|}{ Circa 1864} & \multicolumn{2}{|c|}{ Circa 1843} & \multicolumn{2}{|c|}{ Circa 1864} \\
\hline & Rs. vn. & $\%$ & Rs. vn. & $\%$ & Rs. vn. & $\%$ & Rs. vn. & $\%$ & Rs. vn. & $\%$ \\
\hline Monteagudo. & 105.547 & 37,6 & 83.275 & 48,7 & 169.430 & 63,2 & 36.275 & 40,4 & 95.280 & 57,1 \\
\hline Tudela ........................ & 63.951 & 22,8 & 25.532 & 15,0 & 39.836 & 14,9 & 13.532 & 15,1 & 25.496 & 15,3 \\
\hline Tulebras ....................... & - & - & 20.872 & 12,2 & - & - & 12.372 & 13,8 & - & - \\
\hline Las Arcos .................. & 30.748 & 11,0 & 8.573 & 5,0 & - & - & 3.373 & 3,7 & - & - \\
\hline San Adrián .................... & 26.259 & 9,4 & 6.570 & 3,8 & 16.424 & 6,1 & 3.570 & 4,0 & 12.618 & 7,6 \\
\hline Cascante .................. & 30.702 & 11,0 & 9.034 & 5,3 & 13.586 & 5,1 & 7.034 & 7,8 & 11.525 & 6,9 \\
\hline Aoiz & - & - & 7.341 & 4,3 & 8.817 & 3,3 & 5.841 & 6,5 & 6.707 & 4,0 \\
\hline Corella ........................ & 12.563 & 4,5 & 4.796 & 2,8 & 9.371 & 3,5 & 3.496 & 3,9 & 7.341 & 4,4 \\
\hline Cintruénigo .............. & 4.962 & 1,8 & 2.655 & 1,6 & 5.800 & 2,2 & 2.515 & 2,8 & 4.546 & 2,7 \\
\hline Olite ........................... & 771 & 0,3 & - & - & - & - & - & - & - & - \\
\hline Peralta .......................... & 4.927 & 1,8 & 2.178 & 1,3 & 4.613 & 1,7 & 1.878 & 2,1 & 3.348 & 2,0 \\
\hline Total......... & 280.431 & 100,0 & 170.826 & 100,0 & 267.877 & 100,0 & 89.886 & 100,0 & 166.861 & 100,0 \\
\hline
\end{tabular}

Nota: En 1864, la fuente suma 10.257 rs. vn. de ingresos en la administración de Aoiz, pero la suma de las partidas que lo componen no da esa cifra, sino 8.817 rs. vn.

FUENTE: AMSA, General, lg. 6-7, c. 5; Indiferentes, núm. 2, lg. 3.

mismo en un área más compacta en torno a la localidad de Monteagudo y al curso medio del río Queiles. Si en 1794-1798, el 37,6 por 100 del ingreso bruto de la casa procedía de esa administración, hacia 1843 alcanzaba el 48,7 por 100 y en 1864 se llegaba al 63,2 por 100. En términos netos, descontando los gastos ordinarios de la administración, su importancia descendía hasta el 40,4 y 57,1 por 100 en 1843 y 1864 , respectivamente, pero continuaba revelando el considerable esfuerzo inversor que, para la adquisición de nuevas fincas o la capitalización de las mismas, se había venido desplegando en esa localidad desde los primeros años del Ochocientos. Hora es ya, por tanto, de decir algo más sobre este pueblo y sobre el poder, ahora más económico que político, del marqués sobre el mismo. 


\section{MONTEAGUDO. EL ESTADO SEÑORIAL DEVIENE COTO REDONDO}

\subsection{Vidas y haciendas bullen bajo el castillo}

Al pie del cerro coronado por el castillo de los señores de Monteagudo - arruinado durante la guerra de Sucesión y reconstruido desde 1766se apiñaba un corto conjunto de casas (97 en 1607, 106 en 1812). El vecindario que en él vivía - 383 en 1768,436 en 1786,500 en $1802^{22}$ pocas alternativas hallaba a su alcance más que cultivar los campos regados por el Queiles y sus acequias (Calchetes y Naón) durante los estrictos turnos de riego de la albala y aventurarse a sembrar algunos años en los Montes de Cierzo, donde también podían sostener algunos ganados. Movimientos estacionales para trabajar en los pueblos del entorno o la recogida de frutos y leñas de los montes comunes completaban las posibilidades para redondear los ingresos familiares.

El catastro fonciario que los franceses mandaron elaborar en 1811 permite retratar la estructura social en ese momento. Los 140 contribuyentes de la villa, que venían a disfrutar por término medio de una renta anual de $658 \mathrm{rs}$. vn., traducen una composición media del ingreso que recaía en mayor grado sobre el trabajo a jornal ( 30 por 100 ), sobre la propiedad rústica (24 por 100) y sobre los arrendamientos de tierras (15 por 100). Las situaciones personales dentro de la comunidad vecinal eran, sin embargo, muy diversas, con esa mitad exacta de las familias, que declaraban rentas entre 400 y 600 reales, dependiendo en un 66 por 100 del jornal, mientras los 39 contribuyentes que no alcanzaban los 2.500 reales dependían en mayor grado de los ingresos no agrarios (32 por 100) y de los arrendamientos (22 por 100) que sumaban a la tierra propia (26 por 100). Por encima de ese umbral, cuatro propietarios que arrendaban algunos grandes quiñones obtenían lo sustancial de sus tierras (37 por 100) y de sus ganados ( 24 por 100$)$. En fin, una comunidad vecinal internamente diferenciada en la que, sin embargo, no encontramos tipos sociales puros: los jornaleros tienen a menudo una casa y alguna parcela en propiedad, habitualmente con carga de censo, arriendan también alguna porción y completan ingresos con algún animal; los arrendatarios no presentan un perfil menos complejo, $y$ los pudientes locales se revelan como propietarios, arrendatarios y rentistas a un tiempo (de cásas o tierras), ganaderos y administradores, abogados o comerciantes.

\footnotetext{
22 García Zúñiga (1997, pp. 173, 196).
} 


\section{CUADRO 5}

Monteagudo, 1812. Distribución de la renta catastral según su origen entre grupos de residentes $y$ forasteros (datos en rs. un.)

\begin{tabular}{|c|c|c|c|c|c|c|c|c|c|}
\hline Renta (rs. vn.) & Núm. & Urbana & Pecuaria & Rústica & Amiendos & Jomales & Otros & Total & $\%$ \\
\hline $0-100 \ldots \ldots \ldots \ldots \ldots \ldots$ & 10 & 303 & 36 & 179 & - & - & - & 518 & 0,3 \\
\hline $00 \ldots \ldots \ldots \ldots \ldots$ & 16 & 1.134 & 30 & 1.743 & 132 & 480 & - & 3.519 & 1,9 \\
\hline $400-500 \ldots \ldots \ldots \ldots \ldots$ & 38 & 264 & 186 & 970 & 837 & 14.927 & 360 & 17.544 & 9,4 \\
\hline . & 33 & 1.720 & 135 & 3.531 & 2.789 & 8.428 & 1.245 & 17.849 & 9,6 \\
\hline $00 \ldots \ldots \ldots \ldots$ & 27 & 1.675 & 99 & 5.504 & 4.095 & 3.365 & 5.117 & 19.855 & 10,6 \\
\hline $00 \ldots \ldots \ldots$ & 12 & 1.124 & 465 & 3.744 & 3.783 & 350 & 6.440 & 15.906 & 8,5 \\
\hline $10 \ldots \ldots \ldots$ & 2 & 906 & 900 & 1.329 & - & - & 2.460 & 5.595 & 3,0 \\
\hline $5.000-10.000 \ldots \ldots \ldots$. & 2 & 756 & 3.111 & 4.898 & 2.363 & - & 150 & 11.278 & 6,0 \\
\hline & 140 & 1092 & & & & & & & 49,4 \\
\hline Porcentaje.. & - & 8,56 & 5,39 & 23,79 & 15,21 & 29,93 & 17,13 & 100,0 & - \\
\hline & 86 & 330 & 一 & & - & - & & & 10,4 \\
\hline Marqués ................. & 1 & 5.643 & - & 63.689 & - & - & 5.738 & 75.070 & 40,2 \\
\hline & 227 & 13.855 & 4.962 & & 13.999 & 27.550 & 26.031 & 186.510 & 100,0 \\
\hline Porcentaje ................. & - & 7,43 & 2,66 & 53,68 & 7,51 & 14,77 & 13,96 & 100,0 & - \\
\hline
\end{tabular}

En «Otros» se incluyen rentas procedentes del ejercicio del comercio o la artesanía, las conductas de facultativos (médico, albéitar, herrero, maestro, etc.) y las rentas decimales.

FUENTE: APN, Cascante, Valentín Urbasos, 1812-1897.

Fuera del círculo del vecindario, un conjunto de 86 forasteros participaba también de la riqueza del pueblo, aunque por vías y en proporciones no menos diversas. Poco tenían que ver, en efecto, el pequeño propietario de la localidad vecina con el hacendado, el hidalgo o el comerciante de las villas y ciudades del contorno o de la corte o con los obispos de Tarazona y Tudela, que compartían los diezmos con el marqués. Por encima de todos ellos, los ausentes amos del castillo reunían dos quintas partes de la renta catastral de la localidad, que llegaba al 64 por 100 en la renta rústica.

El patrimonio de José María Magallón Armendáriz alcanzaba en ese momento las 283 ha., treinta y cuatro más que las que arrojaba el apeo confeccionado en 1800, ajustándose esta cifra a la extensión de los bienes libres de reciente adquisición. La mayor parte eran tierras de pan llevar: agostíos que se sembraban dos años seguidos y se dejaban descansar el tercero, barbechos que seguían un riguroso año y vez, trasañales que descansaban dos de cada tres y albares sembrados en el monte. El 29 por 
100 restante, cuyo peso relativo había crecido desde el último inventario, eran viñedos y olivares que los capataces del marqués se encargaban de cultivar con las yuntas de casa y con mano de obra alquilada.

La política de compraventas explica el continuado aumento del patrimonio de los Magallón (si exceptuamos el inventario de 1845 que no recoge los bienes libres). A lo largo del Ochocientos la casa añadiría 51 ha. a las disfrutadas en 1800 y durante el primer tercio del siglo $\mathrm{XX}$, en especial tras la favorable coyuntura de la Gran Guerra, aún sumarían otras 43 ha., con un 20 y un 14 por 100 de incremento respectivamente. Si a lo largo de esos ciento treinta años habían incorporado casi cien hectáreas a lo que ya disfrutaban en la localidad, es obvio que ello se había producido en detrimento de los propietarios forasteros o de la comunidad vecinal ${ }^{23}$. Ésta había seguido creciendo en número durante el XIX (1192 habitantes se alcanzaban en 1887 , doblando los de 1802) pero el número de propietarios se mantenía estable ( 250 incluyendo vecinos y forasteros en 1889), con lo que cada vez más familias de la villa se encontraban en una precaria situación que dependía del arriendo o del jornal.

Los marqueses de San Adrián lograron reforzar su dominio a nivel local, sustituyendo un poder señorial, es decir, fundamentalmente político, por un control mercantil. El marqués se aseguraba un cierto monopolio de la oferta de tierra en alquiler y de la mayor parte de la demanda de mano de obra - para sus más de cien hectáreas de explotación directa en viñedos y olivares-, a la vez que, con sus setenta casas, otras tantas familias, o más, pasaban a depender del marqués para su vivienda. La naturaleza de ese nuevo poder, que permitía tejer redes de clientelas y asegurar lealtades, ya había sido expresada por el apoderado de la casa en 1799:

«En este pueblo se necesita un administrador bien dotado, de mucha providad y zelo, que con su política contenga el abuso que los vezinos y govierno hacen de la bondad de S. E.; lo que no es difícil, pues siendo los más colonos y dependiendo la subsistencia de ellos de lo que trabajen para la casa, deverá elegirse para los arriendos y emplearlos en las labores de la hacienda aquellos más adictos a los intereses de S. S. ${ }^{a}$, con lo que quedarán

${ }^{23}$ En 1850 , los 137 contribuyentes vecinos reunían todavía el 48,4 por 100 del capital imponible mientras que el marqués disfrutaba de otro 42,7 por 100 (frente al 49,4 y 40,2 por 100 de 1812); la erosión del patrimonio de los vecinos -más si tenemos en cuenta el aumento demográfico de la villa que alcanzaba los 909 habitantes en 1860 - y la de los forasteros (ahora, 59 con el 8,9 por 100 del capital imponible) es bien elocuente (AAN, cj. 16190). 


\section{CUADRO 6}

Superficie en propiedad de los marqueses de San Adrián en Monteagudo y orientación productiva, 1607-1932

\begin{tabular}{|c|c|c|c|c|c|c|c|c|c|}
\hline & \multicolumn{2}{|c|}{ Herbáceos } & \multicolumn{2}{|c|}{ Viñedo } & \multicolumn{2}{|c|}{ Olivar } & \multicolumn{2}{|c|}{ Total } & \multirow{2}{*}{ Indices } \\
\hline & $\mathrm{Ha}$. & $\%$ & $\mathrm{Ha}$. & $\%$ & $\mathrm{Ha}$. & $\%$ & Ha. & $\%$ & \\
\hline 1607. & 180,50 & 74,9 & 9,43 & 3,9 & - & - & 241,14 & 100 & 96,8 \\
\hline 1800 (vínculos).. & 196,46 & 82,4 & 22,15 & 9,3 & 19,81 & 8,3 & 238,42 & 100 & - \\
\hline 1800 (libres) ....... & 10,77 & 100,0 & - & - & - & - & 10,77 & 100 & - \\
\hline $1800 \ldots \ldots \ldots \ldots$ & 207,23 & 83,2 & 22,15 & 8,9 & 19,81 & 8,0 & 249,19 & 100 & 100,0 \\
\hline $1811(\mathrm{v}$ & 172,23 & 69,8 & 21,74 & 8,8 & 52,94 & 21,4 & 246,91 & 100 & - \\
\hline 1811 (libres) ....... & 29,75 & 82,9 & 5,16 & 14,4 & 0,99 & 2,7 & 35,90 & 100 & - \\
\hline $1811 \ldots \ldots \ldots \ldots$ & 201,98 & 71,4 & 26,90 & 9,5 & 53,93 & 19,1 & 282,81 & 100 & 113,5 \\
\hline $1845 \ldots \ldots \ldots \ldots \ldots \ldots \ldots$ & 194,05 & 74,2 & 24,78 & 9,5 & 42,70 & 16,3 & 261,53 & 100 & 104,9 \\
\hline $1869 \ldots \ldots \ldots \ldots \ldots \ldots$ & 195,96 & 67,5 & 24,52 & 8,5 & 69,74 & 24,0 & 290,22 & 100 & 116,5 \\
\hline $1891 \ldots$ & 193,83 & 64,9 & 28,67 & 9,6 & 76,16 & 25,5 & 298,66 & 100 & 119,8 \\
\hline $1898 \ldots$ & 186,05 & 62,0 & 37,24 & 12,4 & 76,86 & 25,6 & 300,15 & 100 & 120,4 \\
\hline $1912 \ldots$ & 209,82 & 69,1 & 19,83 & 6,5 & 73,98 & 24,4 & 303,63 & 100 & 121,8 \\
\hline & 201,69 & 66,2 & 27,32 & 9,0 & 75,72 & 24,8 & 304,73 & 100 & 122,3 \\
\hline $1932 \ldots \ldots$ & 203,40 & 59,2 & 64,10 & 18,7 & 75,74 & 22,1 & 343,24 & 100 & 137,7 \\
\hline
\end{tabular}

Fuentes: 1607 (AGN, Comptos, Papeles sueltos); 1800 (APN, Tudela, J. J. Zapata, 1800, p. 1); 1811 (APN, Cascante, V. Urbasos, 1812, p. 41); 1845, 1869 y 1935 (AMSA, Indiferentes, núm. 2, lg. 3); 1891, 1898 y 1912 (AAN, Catastro, lb. 109); 1917 (AMT, Juzgado de 1." Instancia, Civil, 1917, núm. 18, cj. 1); 1932 (AAN, cj. 16445).

los restantes imposibilitados de pensar en proyectos que incomoden al $\mathrm{Sr}$. Marqués, porque les faltará los medios de ejecutarlo» 24 .

\subsection{Tierra cedida y concedida: quiñoneros, parcelarios y enfiteutas}

Una parte sustancial del patrimonio estaba orientado a la captación de rentas tanto en especie como en metálico. Al menos esas doscientas hectáreas que a comienzos de la centuria aparecen dedicadas a cultivos herbáceos eran objeto de arrendamientos a corto plazo a cambio de una renta anual en grano. Operando en un mercado abierto, estas líneas de ingreso fundadas en una propiedad alodial encajaban, por tanto, en un esquema plenamente capitalista. Pero al iniciarse el Ochocientos la estruc-

\footnotetext{
${ }^{24}$ AMSA, cj. 59/1.
} 
tura de rentas del linaje en Monteagudo era notablemente más compleja. Junto al grano ingresado por arrendamientos de tierras, que en la primera década del siglo representaba apenas el 56 por 100 del trigo ingresado en las paneras, el cargo de Monteagudo registraba también partidas heterogéneas englobables bajo la etiqueta de derechos feudales, así como otras que reportaba el arrendamiento de los monopolios señoriales, algunos censos enfitéuticos (en grano, dinero o gallinas) y hasta la devolución de la semilla prestada a los colonos ${ }^{25}$.

Los tributos señoriales eran básicamente de dos tipos: los que, reducidos a trigo y cebada, se recaudaban en garba o haces en el propio campo, y los que, incluyendo además alubias y cáñamo, se cobraban en grano en las eras. Los tributos en garba procedían «de las tierras arrendadas y a derechos sin renta, que son las llamadas cristianiegas y moriegas, según los derechos de octavo, sexto, quinto, quarto y tercio, que se cobra en el Quarteo, conforme la calidad de cada tierra». Los octavos en grano los pagaban «las tierras moriegas que no deben diezmo ni primicia y en su lugar se paga este derecho al Señorío en reconocimiento del directo dominio de ellas, a más del censo perpetuo con que están cargadas, por estar dadas a enfiteusis» ${ }^{26}$. En la hacienda privativa del marqués, estas rentas proporcionales se superponían al producto de los arrendamientos de las propiedades, de tal forma que en algunos casos el señor llegaba a cobrar tres tipos de rentas sobre una misma parcela: lo que correspondía al diezmo en las tierras moriegas, el tributo del quarteo y el alquiler de la heredad. Entre 1820 y 1823 se produjo una drástica reducción de los tributos en grano y la desaparición de los cobrados en garba, aumentándose al mismo tiempo de modo sustancial el trigo obtenido de los arrendamientos. Aunque no he encontrado documentos que lo aclaren, parece como si la vuelta del gobierno constitucional y las negras perspectivas que arrojaba sobre los derechos señoriales hubiesen inducido, con el asentimiento de los colonos (escogidos tal vez entre los «más adictos»), la subsunción de los tributos en el precio de los alquileres de tierras.

${ }^{25}$ El sentido que tenía esta práctica era - como se señalaba en 1856 - «mejorar la calidad de las rentas». Así, cuando a finales de siglo se eliminen los préstamos de simiente (reducidos ya a la mitad en el primer cuarto de la centuria) se añadirá en los contratos de arrendamiento que el trigo de la renta haya de ser «bueno, limpio y seco, con exclusión del... Moro o de la Abundancia».

${ }^{26}$ AMSA (cj. 68, Cuentas de 1800). Las tierras moriegas ( 81 ha. en el apeo de 1607 y 95 ha. en el de 1800) llevaban el estigma de haber pertenecido a los siervos moriscos. Resulta difícil separar lo que en tan confusa tributación correspondía a terrazgos $(27,43$ ha. en el apeo de 1800 «a derechos sin renta») de aquellas garbas y octavos que pesaban sobre tierras cargosas. 
Pero junto a esa simplificación de las rentas, las décadas centrales del XIX vieron aparecer tres nuevos renglones de cargo: los censos enfitéuticos en cuya recuperación y renovación se invirtieron no pocas energías, los cánones perpetuos de los prados repartidos en 1822 que comenzaron a pagarse desde 1848 y las llamadas rentas eventuales que no eran otra cosa que terrazgos (una variedad poco comprometida de aparcería) que se habían estipulado en los años cuarenta para poner en cultivo el monte. Tanto censos enfitéuticos como cánones perpetuos y terrazgos tendieron a desaparecer en las décadas de 1870 y 1880 como consecuencia de luiciones o de compras y ejecuciones por parte del marqués ${ }^{27}$.

$\mathrm{Al}$ margen de las partidas citadas y del trigo que pagaba el arrendatario del molino harinero, lo sustancial de las rentas provenía de los arrendamientos de tierras a corto plazo, que podían adoptar dos modalidades: el arriendo de quiñones o el alquiler de parcelas sueltas. El quiñón, el equivalente de la clásica tenencia o manso, que garantizaba al cultivador una unidad de explotación suficiente, era percibido por el propietario como «un conjunto de tierras de varias heredades de buena, mediana y mala calidad, que se arriendan juntas para hacerlas todas redituables y que nada quede sin cultivo» ${ }^{28}$. Al comenzar el siglo, la hacienda se descomponía en veinte quiñones de dimensión variable que, arrendados a 27 sujetos, reunían 158 hectáreas en 346 parcelas que combinaban distintas calidades de tierra correspondientes a diferentes intensidades de cultivo. Completaban el panorama 19 ha. (un 10,6 por 100 del total) arrendadas por parcelas sueltas a otros sujetos. Cuarenta años más tarde se perciben no pocas variaciones. De entrada, había más tierra en el circuito de arrendamientos —doce hectáreas-, aunque bastantes menos (25,6 ha.) en el modelo de quiñones. La superficie que se alquilaba ahora parcela a parcela, en un mercado mucho más abierto y competitivo por parte de los demandantes (recuérdese el aumento demográfico), se había multiplicado por tres hasta representar el 30 por 100 del total. Pero es que además se observa una modificación tanto en la composición como en el tamaño de los quiñones: se concentran más en las tierras de calidad media en detrimento de las inferiores y superiores (van perdiendo así la función que asignaba el apunte citado), y la extensión media del quiñón se ha reducido en un 7 por 100

${ }^{27}$ En la década en que estas partidas alcanzaron mayor volumen, la de 1850, los censos enfitéuticos aportaban por término medio anual $13 \mathrm{hl}$. de trigo, los cánones de los prados $38 \mathrm{hl}$. y los terrazgos 23,50 hl.; representaban, en suma, un 8,2 por 100 de las entradas de grano. En la última década del siglo, no llegaban a sumar $6 \mathrm{hl}$.

${ }^{28}$ AMSA, Cuentas de 1812, caja 49. 
(de 7,89 a 7,34 ha.) al ampliarse el número de pequeños lotes en perjuicio de los de tamaño medio. Un último apunte es el sustancial incremento del volumen de trigo ingresado y, en consecuencia, el más que notable aumento de la renta del suelo que, en el caso de los quiñones, había crecido en un 62 por 100 . No menos significativo es que la renta media de los alquileres sueltos superase la de los arriendos por lotes afectando, como lo hacía, a una mayor proporción de tierras inferiores: la competencia entre la marabunta de pequeños arrendatarios permitía optimizar la renta del marqués, al tiempo que el mercado de quiñones le permitía apoyarse en un sólido círculo de familias, por lo general pudientes a nivel local al disponer de algunas propiedades, que tenían así razones para estar agradecidas y mantenerse leales. Estas tendencias se confirmaron y acentuaron en las décadas centrales del siglo, ya que hacia 1869-1870 encontramos menos quiñones y más pequeños, más tierra arrendada individualmente y a un precio más elevado.

También se modificaron las condiciones de los contratos de arrendamiento. En 1801 se estipulaba una duración de seis años y el pago, al plazo de la virgen de agosto, no sólo de una renta anual en trigo «bueno y limpio de dar y recibir puestos a su costa en los graneros» del marqués, sino también del «octavo de todos los frutos que cogiere en los agostíos y barbechos moriegos» y la proporción correspondiente a los trasañales moriegos y cristianiegos ${ }^{29}$. El arrendatario se comprometía además a asistir «con su persona y caballerías al quarteo, trilla y recolección siempre que se le avise $[. .$.$] sin estipendio alguno», añadiéndose que «en la misma$ forma deberá ayudar también a entrar el grano en los graneros y la paja en los pajares de este señorío». Se trataba, en definitiva, de un contrato un tanto confuso, que acumulaba sobre unas mismas heredades precios a pagar de diferente naturaleza y origen, y mantenía residuos de las viejas prestaciones en trabajo; no otra cosa es la asistencia del colono con sus caballerías a la trilla, recolección y transporte de las rentas sin remuneración alguna. Esos rasgos arcaicos desaparecerían a mediados de la centuria en un contrato simplificado: plazo por seis años, entrega en el granero de trigo «limpio y bueno», reserva de las hierbas para el propietario, prohibición del subarriendo y de la plantación de leñosos, mantenimiento del arbolado y las infraestructuras de riego, cultivo completo y en tiempo oportuno sin dejar rincones ni ribazos, entendiendo que se hacía a todo riesgo y que el incumplimiento de alguna de las cláusulas permitiria el desahucio por la vía administrativa con aviso previo de quince días.

${ }^{29}$ APN, Tudela, J. J. Zapata, 1801-1802. 


\section{CUADRO 7}

Estructura de los arrendamientos de tierras labrantias en la bacienda de los marqueses de San Adrián en Monteagudo (1801-1845)

\begin{tabular}{cccccccc}
\hline Lotes & $1^{a}$ & $2^{a}$ & $3 .^{a}$ & Total & Trigo & Renta \\
& (núm.) & (ba.) & (ba.) & (ba.) & (ha.) & (bl.) & (bl/ha.) \\
\hline
\end{tabular}

a) 1801-1802

De 10 a 13 ha.

De 7 a 10 ha.

$\begin{array}{lllllll}4 & 8,82 & 22,18 & 15,90 & 46,90 & 96,34 & 2,05\end{array}$

De 5 a 7 ha.

$\begin{array}{lllllll}6 & 12,39 & 23,00 & 15,32 & 50,71 & 119,40 & 2,35\end{array}$

De 3 a 5 ha.

$\begin{array}{lllllll}8 & 10,96 & 29,30 & 11,28 & 51,54 & 122,54 & 2,38\end{array}$

Total quiñones

$4,26 \quad 2,55$

$8,55 \quad 21,52 \quad 2,52$

Parcelas sueltas

$\begin{array}{llllll}78,74 & 45,05 & 157,70 & 359,80 & 2,28\end{array}$

Total.

2

b) 1841-1845

De 10 a 13 ha.

$\begin{array}{llllllll}20 & 33,91 & 78,74 & 45,05 & 157,70 & 359,80 & 2,28\end{array}$

De 7 a 10 ha.

De 5 a 7 ha.

$3,86 \quad 14,93$

De 3 a 5 ha.

$\begin{array}{llll}37,77 & 93,67 & 45,05 & 176,49\end{array}$

Total quiñones

$\begin{array}{r}37,77 \quad 93,67 \quad 45,05 \quad 176,49 \\ \hline\end{array}$

Parcelas sueltas

$\begin{array}{lllllll}3 & 7,23 & 16,62 & 9,88 & 33,73 & 115,76 & 3,43\end{array}$

$\begin{array}{lllllll}6 & 9,36 & 31,42 & 12,76 & 53,58 & 190,30 & 3,55\end{array}$

$\begin{array}{lllllll}4 & 4,65 & 14,30 & 4,10 & 23,06 & 94,86 & 4,11\end{array}$

Total

\begin{tabular}{rrrrrrr}
5 & 4,24 & 15,10 & 2,43 & 21,77 & 86,82 & 3,99 \\
\hline 18 & 25,49 & 77,47 & 29,19 & 132,14 & 487,74 & 3,69 \\
- & 8,77 & 31,55 & 16,35 & 56,67 & 215,55 & 3,80 \\
\hline- & 34,26 & 109,02 & 45,54 & 188,81 & 703,29 & 3,72 \\
\hline
\end{tabular}

c) 1870

De 5 a 7 ha.

\begin{tabular}{rrrrrrc}
5 & 2,86 & 11,41 & 14,22 & 28,49 & 98,03 & 3,44 \\
9 & 5,17 & 20,56 & 7,40 & 33,13 & 146,14 & 4,41 \\
\hline 14 & 8,03 & 31,97 & 21,62 & 61,62 & 244,17 & 3,96 \\
- & 25,85 & 77,39 & 16,96 & 120,21 & 529,55 & 4,40 \\
- & 0,89 & 1,17 & 3,14 & 5,19 & - & - \\
\hline 112 & 34,77 & 110,53 & 41,72 & 187,02 & 773,72 & 4,26 \\
\hline
\end{tabular}

De 3 a 5 ha.

Total quiñones

Parcelas sueltas

Sin arrendatario

Total...

Datos en hectáreas y en hectólitros de trigo.

FuENTE: APN, Tudela, J. J. Zapata, 1801. AMSA, Indiferentes, núm. 2, lg. 3. Para 1870 se han cruzado los datos del inventario de la hacienda con las rentas que detallan los cuadernos de cuentas de ese año. 
CUADRO 8

Evolución de la renta del suelo en Monteagudo (1801-1920)

\begin{tabular}{lrrrrrrrr}
\hline & $1801-05$ & $1806-15$ & $1836-45$ & $1846-55$ & $1866-75$ & $1886-95$ & $1896-00$ & $1916-20$ \\
\hline H1/ha.................. & 2,34 & 2,33 & 3,51 & 3,83 & 4,04 & 4,03 & 4,26 & 5,04 \\
Índice................. 100,00 & 99,57 & 150,00 & 163,67 & 172,65 & 172,22 & 182,05 & 215,38 \\
Índice móvil........ & - & 99,57 & 150,64 & 109,12 & 105,48 & 99,75 & 105,71 & 118,31 \\
\hline
\end{tabular}

FUENTE: AMSA, Cuentas de la administración de Monteagudo y cuadro 6.

La simplificación de las fuentes de ingresos y de las condiciones de los arriendos fue paralela a un incremento del precio de la tierra. Las fechas claves en el aumento de la renta del suelo fueron los primeros años veinte -cuando el hecho decisivo de la supresión del tributo en garba coincidió con la búsqueda de un marco más estable a través de la transacción sobre los prados y el tanteo de una solución política para recuperar los censos enfitéuticos-, los años treinta - decisivos en la reestructuración del patrimonio, con el significativo traslado de la administración general desde Tudela a Monteagudo- - y los primeros años cuarenta (coincidiendo con la supresión del diezmo y a punto de culminar la redefinición patrimonial). Con posterioridad, como ya señalara Robledo para el caso castellano y se puede percibir en otros países, el ritmo alcista comenzó a menguar hasta detenerse en los años ochenta. Pero, lejos de producirse la «derrota del rentista», los años noventa contemplaron, como en Castilla, una reanudación del alza de la renta que se prolongó durante las primeras décadas del siglo xx. En fin, unos derechos de propiedad mejor definidos y unos contratos con un condicionado más claro y simple que reservaba al amo los medios de control suficientes, le facultaron a éste para rentabilizar la coyuntura alcista de mediados de siglo mediante una elevación de sus alquileres ${ }^{30}$.

\subsection{El gentilhombre cultivador de olivares y vinedos}

Durante el primer cuarto del Ochocientos lo que la contaduría ingresaba por los diversos renglones de rentas, censos o luismos en dinero o por ventas de frutos - principalmente trigo- procedentes de rentas o tributos

\footnotetext{
${ }^{30}$ Robledo (1984, pp. 101-215).
} 
venía a representar un 50,3 por 100 del ingreso total. El resto procedía en su mayor parte de la venta de aceite y vino o de sus subproductos, resultado de la explotación directa de un buen número de hectáreas de la hacienda (42 ha. en 1800 , pero 81 ha. ya en 1812) y de la transformación a que era sometida la materia prima obtenida en viñedos y olivares. $\mathrm{Si}$ esta composición de los ingresos ilustra la doble opción, rentista y empresarial, que caracterizaba a la casa, esta segunda faceta no haría sino ampliarse a lo largo de la centuria. La superficie de viñedos y olivares superaba en 1870 las 94 ha. y alcanzaba las 114 ha. en 1898; correlativamente, la venta de los frutos cosechados y transformados llegó a aportar durante el tercer cuarto del siglo el 57 por 100 del cargo, relegando a los ingresos rentistas, que no habían dejado de crecer entretanto, a un 40 por 100. Este avance porcentual del producto de la administración directa supone en cifras brutas el salto desde 40.850 rs. vn. por año durante el primer cuarto del siglo a $92.630 \mathrm{rs}$. vn. en el último; o lo que es lo mismo, se duplicó con creces el ingreso que aportaban olivares y viñedos explotados con mano de obra asalariada a las arcas de la casa.

Esta dimensión cultivadora de los marqueses, que la estructura del gasto de la hacienda refleja con nitidez, no suponía ninguna excepción en el medio social en el que se movían. A lo largo del xIx los testimonios que hallamos apuntan hacia una combinación de estrategias rentistas e inversoras entre la clase propietaria, si bien ciertas coyunturas abonaron el abandono total o parcial del cultivo directo ${ }^{31}$. La nota que caracteriza la gestión directa de los marqueses en su hacienda de Monteagudo durante el xax es la fidelidad a la opción aceitera adoptada desde fines del siglo Xvin. Fue la venta de aceite, en efecto, la que demostró un mayor dinamismo entre los renglones de cargo, pasando de ocupar un tercio del mismo durante los primeros veinticinco años hasta la mitad exacta que exhibe en el tercer cuarto de la centuria. No podía ser de otro modo si consideramos las numerosas inversiones realizadas y las cuidadosas atenciones prodigadas a las empeltrerías y olivares del marqués. Buena parte de las adquisiciones de fincas verificadas durante la primera década - a campesinos endeudados o a la Real Hacienda- se realizaron con la vista puesta en configurar al norte del pueblo un amplio espacio redondo acotable. Permitido ya por

${ }^{31}$ Garrabou, Saguer y Sala (1993); Garrabou, Planas y Saguer (2001); Calatayud, Millán y Romeo (1997), y Carmona Pidal (1995). Los marqueses de San Adrián, por ejemplo, abandonaron el cultivo directo del viñedo en su administración de Cascante en 1821 y no la retomaron hasta 1876 . Un análisis más detenido del cultivo directo del viñedo en Lana (1995). 
ley el cercamiento de fincas destinadas a esos usos, las nuevas unidades parcelarias formadas por agregación de las que ya poseía la casa y de las recientemente adquiridas se rodearian de tapias y bardales para individualizar sus usos (27.535 rs. vn. se desembolsaron en 1807-1808 con ese motivo, incluyendo la compra de 3.000 injertos en Zaragoza), y se plantarían con estacas o con empeltres. Una u otra alternativa, que entre otras cosas variaba el requerimiento de fuerza de trabajo cualificada, daban lugar a plantaciones regulares, lejos ya del recurso tradicional a intercalar pies de olivo en campos o viñedos ${ }^{32}$.

\section{CUADRO 9}

Evolución de la estructura del gasto, del ingreso, del producto líquido y de la inversión en la administración de Monteagudo (1801-1900)

\begin{tabular}{rrrrrrrrrrrr}
\hline \multicolumn{1}{c}{ Salarios Insumos Admón. Manten. Contrib. } & $\begin{array}{c}\text { Total } \\
\text { gasto }\end{array}$ & $\begin{array}{c}\text { Total } \\
\text { ingreso }\end{array}$ & $\begin{array}{c}\text { Producto } \\
\text { liquido }\end{array}$ & $\%$ & Inversión \\
\hline $1801-1810$ & 32,18 & 0,24 & 2,70 & 1,14 & 3,36 & 39,63 & 79,10 & 39,47 & 49,9 & 26,97 \\
$1811-1820$ & 34,29 & 0,19 & 3,34 & 1,00 & 10,46 & 49,29 & 95,47 & 46,18 & 48,4 & 0,35 \\
$1821-1830$ & 28,60 & 1,33 & 3,85 & 2,83 & 1,80 & 38,41 & 55,55 & 17,14 & 30,8 & 1,86 \\
$1831-1840$ & 25,36 & 0,72 & 4,18 & 6,79 & 15,18 & 52,24 & 90,36 & 38,12 & 42,2 & 2,92 \\
$1841-1850$ & 26,39 & 0,15 & 4,16 & 4,60 & 8,06 & 43,36 & 104,17 & 60,81 & 58,4 & 0,46 \\
$1851-1860$ & 33,91 & 1,73 & 5,39 & 15,76 & 19,89 & 76,69 & 158,15 & 81,46 & 51,5 & 4,89 \\
$1861-1870$ & 43,05 & 3,41 & 4,36 & 11,13 & 22,30 & 84,25 & 175,31 & 91,05 & 51,9 & 15,28 \\
$1871-1880$ & 50,70 & 1,12 & 4,26 & 10,14 & 37,03 & 103,25 & 151,28 & 48,03 & 31,7 & 9,93 \\
$1881-1890$ & 57,45 & 1,05 & 5,30 & 6,35 & 38,90 & 109,06 & 161,47 & 52,41 & 32,4 & 23,88 \\
$1891-1900$ & 52,83 & 0,47 & 5,85 & 4,43 & 34,11 & 97,69 & 175,65 & 77,96 & 44,4 & 15,03 \\
\hline
\end{tabular}

Datos en miles de reales vellón.

La columna «Inversión» incluye las partidas de gastos que podemos considerar extraordinarias: compras y permutas de patrimonio, luiciones de censos, plantación y cercado de fincas, compras de mulas, utensilios y maquinaria, construcción de edificios.

FuENTE: AMSA, Cuentas de la administración de Monteagudo.

Las inversiones no se limitaban al cultivo de los campos, sino que abordaban también la transformación del producto. La vieja almazara banal

${ }^{32}$ Artola (1979, p. 33). En el inventario y avalúo de la hacienda de 1845 se registran cuatro parcelas con estas características, que abarcaban 61,88 ha. (incluyendo un embalse de tierra para riego construido en 1828) y se valoraban en 229.280 rs. vn. Su ampliación mediante la compra y adición de parcelas contiguas debió de continuar, ya que en el inventario de 1870 se apeaban 68,74 ha. (un 12 por 100 más) y se valoraban en 74.300 escudos. 
requería gastos continuos de mantenimiento y fue objeto de algunas reformas a lo largo del siglo para ampliar su capacidad. A pesar de eso, resulta significativo que los ingresos derivados de la molturación de olivas ajenas disminuyese drásticamente a lo largo de la centuria: si la maquila proporcionaba por término medio $2.220 \mathrm{rs}$. vn. anuales al arrancar el siglo, hacia 1850 no pasaban ya de $376 \mathrm{rs}$. vn. Más que a la pérdida del monopolio señorial, hay que achacarlo a la especialización olivarera del patrimonio, que obligaba a reservar para la casa toda la capacidad del trujal. Incluso cuando en las últimas décadas del XIX la competencia de otras grasas para usos industriales y la del aceite andaluz para uso de boca, unido a algunas catástrofes coyunturales como la helada de 1887 o la plaga de negrilla, arrojaron sombras sobre el sector, la respuesta de los marqueses no fue abandonar una especialización amenazada, sino, por el contrario, profundizar en la misma mediante inversiones de un calibre desconocido hasta entonces. La almazara, mejorada ya en los cincuenta, recibió importantes inversiones entre 1877 y 1883 para renovar la maquinaria (38.195 rs. vn.) y ampliar la capacidad de almacenamiento (11.975 rs.) incluyendo la construcción de una nueva bodega de aceite (30.550 rs.). En 1886 y 1887 se volvieron a invertir otros 64.755 rs. vn. en reformas interiores y la colocación de una prensa hidráulica, y diez años más tarde se iniciaría un nuevo esfuerzo inversor para mejorar la capacidad productiva instalando nueva maquinaria (46.945 rs. vn. entre 1896 y 1900). De este modo, el capítulo de inversiones, que se había mantenido en torno al 4 por 100 del gasto total entre las décadas de 1830 y 1860 , llegaba a superar ampliamente el 10 por 100 del mismo en las tres últimas décadas de la centuria ${ }^{33}$.

La especialización aceitera requería, además de inversiones puntuales, de una constante preocupación por realizar adecuadamente y a su tiempo tanto las labores ordinarias del cultivo, introduciendo nuevas técnicas (como se hace con la poda en 1838), como las correspondientes a la elaboración del aceite. Junto a los criados fijos de la hacienda - sobrestante y muleros-, el cultivo olivarero requirió contratar un número creciente de jornales que si durante el primer cuarto del XIX se mantenía en 303 por término medio anual para las tareas ordinarias (canterear y regar, labrar o cavar, escocar, podar y esfollinar) y 1.243 para la recolección, en el último cuarto se llegaba a 1.884 para aquellas labores y a 2.194 para la recogida. Siendo ésta la operación más intensiva en trabajo y, por tanto, más costosa en

${ }^{33} \mathrm{Se}$ incluye en esas cifras la adquisición de una prensa de husillo (12.022 rs.) en 1880 y de dos prensas hidráulicas en 1886 (13.796 rs.) y en 1896 (17.940 rs.). 
términos monetarios, se adoptaban estrategias diversas para abaratar costes, como el empleo masivo de mano de obra infantil o femenina o, como fue normal durante las décadas centrales del Ochocientos, el ajuste a destajo. Al mismo tiempo, dado que la producción de la almazara abarcaba tanto aceite de calidad para uso de boca como grasas comunes para alumbrado, los métodos de recolección iban desde muir seleccionando las mejores piezas hasta varear el árbol.

La preocupación por obtener un buen producto no se vería recortada por el aumento de competencia que significó la crisis finisecular. Al contrario, la búsqueda de la calidad se vio reforzada con ello ${ }^{34}$. Aunque las estrategias seguían respondiendo a una lógica patrimonial de conjunto y la producción de aceite estaba lejos de encajar aún en un planteamiento individualizado de empresa, con lo que ello significa de atender tanto a los aspectos de producción como de comercialización, no por ello se hacía caso omiso de las oportunidades para mejorar la salida del producto. Así hay que interpretar la repetida participación del marqués, como otros muchos propietarios que aprovechaban el soporte prestado por el Ministerio de Fomento y por las juntas provinciales dependientes del mismo, en las exposiciones nacionales e internacionales, que le servirían de escaparates para sus aceites de calidad ${ }^{35}$.

La tenacidad con que se mantuvo la explotación directa, aún en una coyuntura depresiva tan larga como la del segundo cuarto del siglo, y la continuidad de la apuesta por la especialización aceitera —que esta familia comparte con otras muchas en ese momento- merecen una reflexión más detenida. El primer factor a considerar tiene que ver con la evolución de las relaciones de intercambio entre los principales productos agrícolas, que favoreció durante el segundo cuarto del siglo $\mathrm{Xx}$ al aceite sobre el trigo y el vino, desencadenando procesos de reasignación de factores y

34 «Aun cuando nada me hubiese advertido V. E. -escribía el administrador de Monteagudo al marqués en noviembre de 1877 - respecto al modo y manera de coger la oliva sola de empeltres para el aceite superior, quitarle las hojas, palos, tierra y demás, ya estábamos en ello, haciéndola fría antes de que fermentase [...] Puede V. E. también estar tranquilo de que no entrará nadie en el trujal sino es los operarios y parroquianos cuando se estén elaborando sus cosechas» (AMSA, cj. 26/4).

${ }^{35}$ Participaron los marqueses con muestras de aceite de empeltre en la Exposición Agrícola de Madrid de 1857 (medalla de bronce), en la Exposición Internacional de Londres de 1862, en la Exposición Franco-Española de Bayona (1864) a la que concurrieron con cuatro tipos de aceite, llevándose sendos diplomas y medallas de oro y plata. Todavía acudirían a la exposición celebrada en Chicago en 1893, donde declaraban disponer de unas existencias para venta de $650 \mathrm{dls}$. al precio de $100 \mathrm{ptas} / \mathrm{hl}$. (BGN, 104-1-4/124; 104-1-4/307). 
recursos productivos a su favor ${ }^{36}$. Además, el estado de los sistemas de transporte -en especial, los que conectaban la provincia a otras zonas productoras capaces de competir con las grasas locales - y el cordón aduanero que rodeaba al Reino hasta 1841 servían para reservar un mercado regional seguro y creciente para los productores de la Ribera. Desde el punto de vista de los procesos de producción, los altos costes iniciales del olivar, debido a las fuertes inversiones necesarias en la plantación de estacadas y empeltrerías así como en la construcción y mobiliario del molino y bodega de aceite, lo ponían fuera del alcance de los modestos cultivadores. $\mathrm{El}$ acceso de éstos a los mismos sólo podía hacerse a través del cultivo promiscuo o bien por medio de arrendamientos o de otras fórmulas de cesión que debían ser, por la propia naturaleza del cultivo, a plazos muy largos. Un contrato corto de cesión ofrecía un nulo atractivo tanto para el posible demandante (producción limitada por el carácter vecero del árbol) como para el oferente (riesgo de daños y descuido de la inversión). Además, los costes laborales de este cultivo eran menos elevados que en el viñedo o los cereales y la punta estacional de la demanda de trabajo se situaba en unos meses en los que la fuerza de trabajo tenía un bajo coste de oportunidad. Puede que fueran estos rasgos los que hicieran que aún en los momentos de dificultades, cuando el coste de producción del viñedo era rápidamente transferido a un colono mediante contratos de arrendamiento o aparcería, el olivar seguía bajo el control directo del propietario.

\section{LA NOBLEZA PROPIETARIA ANTE EL NUEVO ORDEN DE COSAS}

Quienes en los últimos años han abordado a través de la documentación de los propietarios particulares las clásicas cuestiones historiográficas relacionadas con la economía y sociedad rurales del siglo XIX han insistido una y otra vez en la necesidad de revisar los viejos clichés. Los clásicos problemas de las supervivencias feudales, de la revolución burguesa, del atraso agrícola y su responsabilidad en el fracaso de la industrialización o del absentismo y las actitudes rentistas e inmovilistas cobran una nueva dimensión a la luz de estos análisis. Trabajos como los de Héran (1980),

${ }^{36}$ El número de hectólitros de aceite que podían comprarse con un hectólitro de trigo descendió desde 0,171 en 1821-1830 a 0,163 en 1841-1850; por lo que hace al vino, un hectólitro de este producto podía adquirir en los años veinte $0,132 \mathrm{hl}$. de aceite, mientras que dos décadas después esa cantidad había bajado a 0,078 hl. (Lana, 1999, pp. 211-214). 
Bernal (1988), Garrabou, Saguer y Sala (1993), Garrabou, Tello y Vicedo (1993), Garrabou y Planas (1997), Garrabou, Planas y Saguer (2001), Pérez Picazo (1991), Calatayud, Millán y Romeo (1996) (1997) (2000), Carmona Pidal (1995) (2001) o Domínguez Castro (1997), por señalar algunos, revelan una notable flexibilidad de los grandes patrimonios y una atenta disposición de sus titulares para aprovechar de la mejor manera posible las ventajas ofrecidas por los mercados. En muchos casos el resultado de estas actitudes, muy alejadas del reproche tan frecuente del comportamiento antieconómico o no capitalista, fue la gestión directa de una porción más o menos amplia de sus tierras. Claro que, en no pocas ocasiones, los esfuerzos desplegados a mediados del XIX para llevar adelante una explotación agrícola moderna se saldaron con rotundos fracasos, tal vez por un exceso de fidelidad a recetas importadas poco acordes con la realidad física o social del medio en el que se aplicaban ${ }^{37}$. Otras veces, por el contrario, comprobamos la continuidad de los sistemas directos de explotación, aunque en ningún caso llegaron a imponerse como fórmula mayoritaria, ni mucho menos única, de gestión. La cesión de tierra por medio de arrendamientos, aparcerías u otras fórmulas, siguió firmemente anclado como eje de la gestión de estos patrimonios. La renta en especie continuó siendo la modalidad predominante en los contratos agrarios. Ello puede ser interpretado como un signo de arcaísmo, pero desde otra perspectiva esto era también un síntoma del interés del propietario por participar directamente en el juego del mercado, por no perder la oportunidad de valorizar el producto de su propiedad.

De ese conjunto de trabajos microanalíticos resulta también una imagen de heterogeneidad de comportamientos y situaciones que no podemos soslayar. No tenían los mismos condicionantes ni podían adoptar similares estrategias la alta aristocracia retratada por Atienza (1987), Aragón (2000), Baz (1996), Carmona Pidal (1995) (2001), Robledo (1985) o Ruiz Torres (1987), que la nobleza regional de rango medio estudiada por Calatayud, Millán y Romeo (1996) (1997) (2000), Garrabou et alii (1993) (1993)

${ }^{37}$ Garrabou, Saguer y Sala (1993, p. 118) relatan las experiencias del marqués de Sentmenat en el cultivo directo de cereales en la década de 1870 , que no ofrecieron rendimientos acordes a la inversión efectuada y aconsejaron la vuelta al colonato poco después. Carmona Pidal (2001, pp. 218-226) cuenta también los esfuerźos realizados en la misma dirección por el marqués de Alcañices en Cadreita y Cuéllar. Como este autor señala, además de las consideraciones empresariales, el gran propietario decimonónico, fuese aristócrata o burgués, se atribuyó una función social modernizadora a través de las «fincas modelo», como transmisores de los conocimientos y técnicas agrícolas más adecuados a cada región. A este respecto, véase Calatayud (1999). 
(1997) (2001), García Sanz (1991) y Pérez Picazo (1991) o que la expansiva burguesía que retratan Héran (1980), Robledo (1991) o Sabio (1998). En estos últimos faltaban a menudo, aunque no siempre, muchos de los condicionantes que afectaban a los primeros: dispersión patrimonial, complejidad burocrática, indefinición de derechos de propiedad, alto tren de gasto, endeudamiento estructural, [...] Pero aunque no les afectasen los riesgos más graves de todo gigantismo empresarial, no eran menores las necesidades de lograr estructuras de gestión eficientes y de seleccionar (y supervisar) personal adecuado a funciones tan diversas como las requeridas. Conseguir «un administrador bien dotado, de mucha providad y zelo» no era siempre tarea fácil, como comprobaría J. M. Magallón Armendáriz en su azarosa vida. El margen de maniobra de que los agentes locales gozaban, aunque no fuese muy amplio, podía ser utilizado para parasitar al propietario, aunque más a menudo los supuestos desfalcos respondían a problemas de competencia profesional.

Para Monteagudo halló Magallón un eficaz administrador en la persona de Antonio López de Goicoechea, comerciante con casa abierta en Tudela, que por su prudencia en la resolución de los litigios con la villa y su pericia en dirigir la política de inversiones en ese término, fue designado en 1826 administrador general de la casa, prolongándose esta relación por espacio de tres generaciones hasta 1875. Reclutados entre la burguesía local o comarcal, los agentes del marqués - se tratase de administradores de fincas o de simples recaudadores a comisión- garantizaban, bajo la atenta mirada del propietario, un correcto desenvolvimiento del patrimonio, negociando contratos, defendiendo derechos, cobrando rentas y deudas, decidiendo prácticas de cultivo y operando en los mercados. Sobre ellos descansó la estrategia que durante el primer tercio del XIX permitió fortalecer estructuralmente el patrimonio a pesar de las difíciles circunstancias que envolvieron al mismo y a sus titulares.

$Y$ es que por difícil que fuera la situación para la casa, fruto de la caída de ingresos provocada por la contestación social a su dominio o por la evolución de los mercados, y de un endeudamiento más o menos insostenible, el horizonte estratégico trazado a comienzos de la centuria por Magallón Armendáriz y sus consejeros no se perdió de vista, como lo revela la atenta vigilancia del patrimonio a desamortizar de las monjas de Tulebras, las subrogaciones de bienes vinculados efectuadas en Monteagudo, las inversiones no interrumpidas en las empeltrerías y almazara o las negociaciones y acuerdos establecidos con campesinos y enfiteutas de esa localidad para recuperar o transformar censos y derechos señoriales 
trasnochados. Qué duda cabe que estos esfuerzos rindieron sus frutos durante la etapa siguiente. Los Magallón Campuzano pudieron comprobar cómo el cambio de coyuntura les alcanzaba bien situados con un patrimonio compacto y con unos mercados de factores en los que podían operar con ventaja. Una vez asentado el nuevo sistema de relaciones basados en la propiedad y el mercado, el marqués de San Adrián desplegó su doble condición de rentista-comercializador de trigo y de productor-fabricante de aceite y vino, una doble línea de especialización ajustada a unos mercados cuya frontera se expandía, aunque aún con un ritmo moderado. Kesulta tentador postular que en el caso de este patrimonio la segunda de esas vertientes pudo llegar a subordinar a la primera. Así, las nuevas pautas adoptadas en la política de arrendamientos, con el abandono parcial del sistema de quiñones y una oferta atomizada, pudieron venir inducidas por la conveniencia de garantizar la reproducción de una abundante mano de obra que resultaba imprescindible estacionalmente en los olivares y viñedos, sin que por ello dependiese en exclusiva de los salarios pagados. Durante el tercer cuarto del Ochocientos las inversiones en las cuidadas empeltrerías y en la almazara caminaron parejas al incremento del rendimiento patrimonial y los propietarios se encargarían de promocionar sus productos en los foros públicos que se les brindaban. La limitada participación en el cultivo de cereales, ceñida a la alimentación de las bestias de labor, no alentaba la modernización de las técnicas de cultivo del ciclo herbáceo, pero no dejó de cumplir el papel de transmisor de los conocimientos agronómicos a las clases campesinas que los propietarios decimonónicos se atribuían.

En suma, la imagen que traduce el comportamiento de los Magallón durante el siglo XIX queda (y no es una excepción) muy lejos del estereotipo del propietario absentista que el regeneracionismo contribuyó a levantar en un momento histórico marcado por la crisis agraria finisecular, por la pugna en torno a la renta del suelo y por el aplazamiento aquí de la «derrota del rentista».

\section{BIBLIOGRAFÍA}

Aragón Mateos, Antonio (2000): El señor ausenté. El señorio nobiliario en la España del Setecientos, Lleida, Milenio.

ArTola, Miguel (1979): Antiguo Régimen y revolución liberal, Barcelona, Ariel.

Astigarraga, Jesús (1992): «Las sociedades económicas en la segunda mitad del siglo XVU», Gerónimo de Uztariz, núm. 6/7, pp. 25-78. 
ATIENZA, Ignacio (1987): Aristocracia, poder y riqueza en la España moderna. La Casa de Osuna, siglos XV-XIX, Madrid, Siglo XXI.

BAZ VICENTE, M. ${ }^{a}$ Jesús (1996): Señorío y propiedad foral de la alta nobleza en Galicia (siglos XVI-XX): La Casa de Alba, Madrid, MAPA.

Bernal, Antonio Miguel (1988): Economia e historia de los latifundios, Madrid, Espasa.

CAlATAYUd Giner, Salvador (1999): «Difusión agronómica y protagonismo de las elites en los orígenes de la agricultura contemporánea: Valencia, 1840-1860», Historia Agraria, núm. 17, pp. 99-127.

Calatayud, S.; Millán J., y Romeo, M. C. (1996): «La noblesa propietària en la societat valenciana del segle XIX: el comte de Ripalda i la gestió del seu patrimoni», Recerques, núm. 33, pp. 79-101.

- (1997): «El ideal del propietario agrícola y la estabilidad de la sociedad de clases. Discurso y gestión en la nobleza valenciana del siglo XIX», VIII Congreso de Historia Agraria. Preactas, Salamanca, Universidad de Salamanca, pp. 335-348.

- (2000): «El rentismo nobiliario en la agricultura valenciana en el siglo XXX», Revista de Historia Económica, año XVIII, núm. 1, pp. 79-107.

CARMONA PIDAL, Juan (1995): «Las estrategias económicas de la vieja aristocracia española y el cambio agrario en el siglo XIX», Revista de Historia Económica, año XIII, núm. 1, pp. 63-88.

- (2001): Aristocracia terrateniente y cambio agrario en la España del siglo XIX. La Casa de Alcañices (1790-1910), Ávila, Junta de Castilla y León.

Clavero, Bartolomé (1974): Mayorazgo. Propiedad feudal en Castilla, 1369-1836, Madrid, Siglo XXI.

DE LA TORRE, Joseba (1991): Los campesinos navarros ante la guerra napoleónica. Financiación bélica y desamortización civil, Madrid, MAPA.

Domínguez CASTRO, Luis (1997): «La explotación directa como forma de gestión patrimonial en las tierras vitícolas galaicas en los siglos $\mathrm{XIX}$ y $\mathrm{XX} »$, VIII Congreso de Historia Agraria. Preactas, Salamanca, Universidad de Salamanca, pp. 349-362.

FloRISTÁN ImizCOz, Alfredo (1982): La Merindad de Estella en la Edad Moderna. Los hombres y la tierra, Pamplona, Gobierno de Navarra.

GARCIA SANZ, Ángel (1991): «Renta territorial y patrimonio de una casa nobiliaria en la Castilla del siglo XIx: los marqueses de Lozoya, 1808-1896», en P. SAAVEDRA y R. Villares (eds.), Señores y campesinos en la peninsula ibérica, siglos XVIII-XX. 1. "Os señores da terra», Barcelona, Crítica, pp. 173-200.

GarCia ZúNIGA, Mario (1997): Estadísticas históricas de Navarra. Hacienda, población y precios (siglos XVI-XVII), Pamplona, Gobierno de Navarra.

Garrabou, R.; Saguer, E., y SalA, P. (1993): «Formas de gestión y evolución de la renta a partir del análisis de contabilidades agrarias: los patrimonios del Marqués de Sentmenat en el Vallés y Urgell (1820-1917)», Noticiario de Historia Agraria, núm. 5, pp. 97-126.

Garrabou, R.; Tello, E., y Vicedo, E. (1993): «De rentistas a propietarios: la gestión de patrimonios nobiliarios en el último ciclo de la renta feudal en Cataluña (1720-1840)», en E. SARASA y E. SerRano (eds.), Señorío y feudalismo en la Península lbérica, Zaragoza, Fernando el Católico, vol. II, pp. 567-604. 
Garrabou, R., y Planas Maresma, J. (1997): «La aparcería y la gestión de la gran propiedad territorial en la Cataluña contemporánea», VIII Congreso de Historia Agraria. Preactas, Salamanca, Universidad de Salamanca, pp. 379-402.

Garrabou, R.; Planas, J., y Saguer, E. (2001): Un capitalisme impossible? La gestió de la gran propietat agrària a la Catalunya contemporània, Vic, Eumo.

HéraN, François (1980): Tierra y parentesco en el campo sevillano:La revolución agrícola del siglo XIX, Madrid, MAPA.

Hernández Montalbán, Francisco J. (1999): La abolición de los señorios en España (1811-1837), Madrid, Biblioteca Nueva.

LANA BERASAIN, José Miguel (1995): «Trabajo, técnica y mercado en la viticultura navarra: los viñedos del Marqués de San Adrián en Monteagudo durante el siglo XIX», Noticiario de Historia Agraria, núm. 10, pp. 135-163.

- (1999): Estadísticas Históricas de Navarra. El sector agrario navarro (1785-1935). Cultivo, ganadería, propiedad y mercados, Pamplona, Gobierno de Navarra.

- (2002): «Afanes y recompensas del cuitado señor don José María Magallón y Armendáriz, o la remodelación de un patrimonio aristocrático en el siglo XIX», en H. Casado y R. Robledo (eds.), Fortuna y negocios. Formación y gestión de los grandes patrimonios (siglo XVI-XX), Valladolid, Universidad de Valladolid, pp. 165-189.

Martínez Monje, Juan (1947): Historia de la Villa de Monteagudo (Navarra) y de la imagen de la Virgen del Camino y de su Santuario (en la misma Villa), Pamplona, Jesús García.

MerCader Riba, Juan (1983): José Bonaparte, rey de España. 1808-1813. Estructura del Estado español bonapartista, Madrid, CSIC.

PaRIas SÁINZ de Rozas, Maria (1991): «La pervivencia de las estrategias "vinculares", en las transmisiones testamentarias de la segunda mitad del siglo XIX. El caso del marquesado de Grañina, 1850-1875», en P. SaAvedra y R. Villares (eds.), Señores y campesinos en la península ibérica, siglos XVIII-XX. 1. «Os señores da terra», Barcelona, Crítica, pp. 38-61.

PÉrez PicAzo, M. ${ }^{\text {a }}$ Teresa (1990): El mayorazgo en la bistoria económica de la región murciana, expansión, crisis y abolición (siglos XVII-XIX), Madrid, MAPA.

- (1991): «Riqueza territorial y cambio agrícola en la Murcia del siglo XIX. Aproximación al estudio de una contabilidad privada. (Circa 1800-1902)», Agricultura y Sociedad, núm. 61, pp. 39-96.

Robledo HeRnández, Ricardo (1984): La renta de la tierra en Castilla la Vieja y León (1836-1913), Madrid, Banco de España.

- (1985): «Desamortización y Hacienda pública en algunos inventarios de grandes terratenientes», en A. Garcí SANZ y R. Garrabou (eds.), Historia agraria de la España contemporánea. 1. Cambio social y nuevas formas de propiedad (1800-1850), Barcelona, Crítica, pp. 395-432.

- (1991): «E.l ascenso de una burguesía agraria: los "granjeros". Salamanca, 1780-1840", en P. SaAvedra y R. VillareS (eds.), Señores y campesinos en la península ibérica, siglos XVIII-XX. 1. «Os señóres da terra», Barcelona, Crítica, pp. 218-238.

Ruiz TORRES, Pedro (1987): «Patrimonios y rentas de la Nobleza en la España de finales del Antiguo Régimen», Hacienda Pública Española, núm. 108/109, pp. 293-310. 
SABIO AlCUtén, Alberto (1998): «El capitalisme agrari a través de la renda en una agricultura orgànica. Les estrategies d'un ministre a finals del segle XIX a l'Aragó», Recerques, núm. 37, pp. 57-80.

SOla LASHERAS, Esteban (1998): «José María Magallón Mencos, VI marqués de San Adrián (1735-1799)», Revista del Centro de Estudios Merindad de Tudela, núm. 9, pp. 131-156.

Tello i Aragay, Enric (1992): «Renta señorial y renta de la tierra en la última etapa del Antiguo Régimen en Cataluña», Noticiario de Historia Agraria, núm. 4, pp. 283-314.

- (1997): «La conflictividad social en el mundo rural catalán, del Antiguo Régimen a la Revolución liberal, 1720-1833», Noticiario de Historia Agraria, núm. 13, pp. 89-104.

Usunariz GaRAYOA, Jesús M. ${ }^{a}$ (1997): Nobleza y señoríos en la Navarra Moderna. Entre la solvencia y la crisis económica, Pamplona, Eunsa.

Yanguas y Miranda, José (2000): Diccionario de Antigüedades del Reino de Navarra, Pamplona, Gobierno de Navarra, 3 vols.

\section{ABREVIATURAS}

AAN Archivo Administrativo del Gobierno de Navarra (Pamplona).

AGN Archivo General de Navarra (Pamplona).

AMSA Archivo del Marqués de San Adrián (Tudela).

AMT Archivo Municipal de Tudela (Tudela).

APN Archivo de Protocolos de Navarra (Pamplona y Tudela).

BGN Biblioteca General de Navarra (Pamplona).

cj. caja.

ha. hectáreas.

hl. hectólitros.

lb. libro.

lg. legajo.

rs. vn. reales vellón. 